\title{
Yabancı dil olarak Türkçe öğretiminde yeni bir model: Kültür Günleri
}

\section{Emre YAZICI 1}

\section{Talha GÖKTENTÜRK²}

APA: Yazıcı, E.; Göktentürk, T. (2020). Yabancı dil olarak Türkçe öğretiminde yeni bir model: Kültür Günleri. RumeliDE Dil ve Edebiyat Araştırmaları Dergisi, (19), 48-77. DOI: 10.29000/rumelide.752111.

\section{Öz}

Yabancı dil olarak Türkçenin öğretimi için yeni bir modelin geliştirilmesinin amaçlandığı bu çalışmada Kültür Günleri modelinin geliştirilmesine çalışılmıştır. Uygulama odaklı aksiyon araştırması modelinde tasarlanan süreçte önce 2016-2017 eğitim-öğretim yılında C1 seviyesindeki 7 öğrenci ve 5 hoca ile kültür aktarımı hakkındaki görüşlerini belirlemek için iki ayrı görüşme yapılmıştır. Aynı dönemde araştırmacılar tarafından tutulan araştırmacı günlüklerinde, görüşmelerden elde edilen verilerle örtüşecek şekilde, katılımcıların etkinlikler yönünden eğitimöğretim sürecini zayıf bulduğu, kültür aktarımı hususunda Türk kültürünün öğretimi kadar kendi kültürlerini de tanıtmak istedikleri belirlenmiştir. Ayrıca kültür aktarımına dayalı etkinliklerin tasarlanmasının dil öğrenimi sürecini pozitif yönde etkileyebileceği sonucuna varılmıştır. Elde edilen veriler doğrultusunda 4 dil becerisini kapsayacak ve iki yönlü kültür aktarımını temin edecek Kültür Günleri modelinin geliştirilme sürecine başlanmıştır. 2016-2017 yılında Yıldız Teknik Üniversitesi Dil Atölyesi bünyesinde gerçekleştirilen Kültür Günleri’ndeki gözlem kayıtları katılımcıların Türkçe öğrenmeye yönelik tutumlarını pozitif yönde geliştirdiğini göstermektedir. 2017-2018 eğitim öğretim yılında ise sürecin dil becerilerini geliştirmesi için daha uzun süreli bir uygulamaya ihtiyaç duyduğu görülmüş ve mentorluk süreci ile Kültür Günleri’ne hazırlık sürecinin de planlanması sağlanmıştır. Böylece süreç 10 haftalık bir periyoda yayılmıştır. Kültür Günleri sürecinin tamamlanmasından sonra $\mathrm{C} 1$ seviyesindeki 20 katılımcı öğrenci ile görüşme çalışması yapılmış ve veriler içerik analizi ile bulgulaştırılmıştır. Araştırmacı günlükleri ve gözlem verileri ile örtüşen sonuçlara göre Kültür Günleri yabancı dil olarak Türkçe öğrenen 20 katılımcının 4 dil becerisini pozitif yönde etkilemiştir. Teklif edilen modelin yabancı dil olarak Türkçe öğretimi yanında farklı dillerin ikinci dil ve yabancı dil olarak öğretiminde fayda sağlayacağı da söylenebilir.

Anahtar kelimeler: Kültür günleri, yabancı dil olarak Türkçe öğretimi, dil becerileri, kültür aktarımı

\section{A new model in teaching Turkish as a foreign language: Culture Days}

\author{
Abstract \\ In this this study, we aimed to develop Culture Days model for Turkish teaching to foreigners. The \\ study was designed as action research. Firstly, we conducted a focus group interview with $7 \mathrm{C} 1$ level \\ students in academic year 2016-2017. Besides, via research diaries, we reached the similar findings \\ like having a poor education process with regard to activities. The participants also stated that they \\ 1 Arş. Gör., Yıldız Teknik Üniversitesi, Eğitim Fakültesi, Türkçe Eğitimi ABD, (İstanbul, Türkiye), \\ 78yaziciemre@gmail.com, oooo-0002-3884-372X [Makale kayıt tarihi: 24.03.2020-kabul tarihi: 20.06.2020; DOI: \\ 10.29000/rumelide.752111] \\ 2 Arş. Gör., Ylldı Teknik Üniversitesi, Eğitim Fakültesi, Türkçe Eğitimi ABD (İstanbul, Türkiye), \\ talhagoktenturk@gmail.com,oooo-0002-8619-0698


want opportunities to transfer their cultures. Based on these findings, we concluded that an activity based on the foreign students' culture could be helpful to improving their Turkish language skills. In line with the data obtained, the development process of the Culture Days model has begun. The observation records of the Culture Days conducted by Yldız Technical University Language Workshop in 2016-2017 is a positive way to improve the attitudes of the participants towards learning Turkish. In the 2017-2018 academic year, we determine that the process needed a longer term in order to improve the language skills, and the preparation process added to Culture Days model thanks to attendance of mentors. Thus, the process spread over a 10-week period. After the Cultural Days process, we interviewed 20 B2 level participants and the data were analyzed by content analysis. According to the results coinciding with the researcher's diaries and observation data, Culture Days positively affected the 4 language skills of 20 participants. Finally, the proposed model can be beneficial in teaching different languages as a second language and foreign language.

Keywords: Culture days, Turkish teaching to foreigners, language skills, culture transfer

\section{Giriş}

Kültür, milletlerin ferden yaş, cinsiyet ve eğitim gibi özelliklerini ve makro seviyede de bütün milleti ilgilendiren refah seviyesi ve hürriyet gibi değişkenlerini etkilemeye devam etmektedir (Steel \& Taras, 2010). Nitekim insanların eğitim-öğretim sürecindeki motivasyon kaynaklarının belirlenmesi (Dekker \& Fischer, 2008), dilde akıclık (Oberg \& Ramīrez, 2006) gibi hususlarda kültürün etkileyici rolünün sürdüğü görülmektedir. Eğitim sürecinde kültürün boyutlarından biri olan ferdiliğe karşı kolektif hareket etme (Hofstede \& Bond, 1984) eğitim kurumlarında ferdi olarak yapılacak etkinliklerle eğitim kurumunun tamamına yönelik olarak yapılan etkinliklerin çerçevesini etkilemeye devam etmektedir. Bilhassa bir sosyokültürel yapı içerisinde yetişmiş bir fert farklı sosyokültürel yapıdan gelen biri ile etkileşime girdiğinde kültür çatışmaları yaşanabilmektedir (Triandis, 2018). Bununla birlikte yapılan araştırmalar, bir kurum kültürünün millî kültürden gelen farklılıkları azaltarak kendi kültüründe paydaşlarını birleştirecek güce sahip olabileceğine işaret etmektedir (Jacks, Wallace, \& Nemati, 2012).

Beşinci dil becerisi olarak ele alınan kültür yabancı dil eğitiminin dinleme, okuma, konuşma ve yazma becerilerini tamamlayan ve şekillendiren bir unsurdur (Kramsch, 1991). Bu sebeple yabancı dil öğretimi sürecinde kültür temelli etkinliklerin kullanılması etkili bir öğrenme sürecinin sağlanmasında ve dil becerilerinin geliştirilmesinde faydalıdır (Scheu, 1996). Bu sebeple hedef dil, kültürü ile verilmelidir (Barm, 2004).

Türkçenin yabancı dil olarak öğretimi sürecinde çeşitli problemler yaşandığı görülmektedir. Farklı kültürlerden gelen öğrencilerin yabancı bir dil olarak Türkçeyi algılama şeklinin farklı olması iletişim boşluğu doğurmaktadır (Pilanci \& Saltık, 2018). Öğrenme sürecinde motivasyonun sağlanmasında oyunlu ve eğlenceli bulunan etkinlikler fayda sağlamakla beraber birbirine benzeyen etkinlikler motivasyonu düşürmektedir (Biçer, 2016). Öğrenmenin alt başlıklarından olan yazma sürecinde ise katılımcllar sözcük, cümle ve paragraf seviyesinde metin oluşturma problemi yaşamaktadırlar (Tiryaki, 2017). Konuşma becerisi bakımından da hazırlıksız konuşma sürecinde öğrencilerin kaygı oranının yüksek olduğu görülmektedir (Tunçel, 2015). Dinleme ve okuma yönünden de katılımcıların kaygı taşıdıkları belirlenmiştir (Altunkaya, 2017). Öğrencilerin anlama becerileri ile Türkçeye yönelik ilgi ve motivasyonlarında anlatma becerilerine göre daha yüksek seviyede ve pozitif yönde ilişki mevcuttur ve anlatma becerilerinin oluşturduğu kaygının anlama becerilerindeki yüksek ve pozitif yöndeki korelasyona sebep olduğu söylenebilir (Karatay \& Kartallığlu, 2016). 
Kültür aktarımında ise yabancı dil olarak Türkçe öğreten öğretmenlerden oluşan çalışma gruplarında Türk kültürü ile ilgili metinlerin ve uygulamaların zenginleştirilmesine yönelik görüşler elde edilmiştir (Moralı \& Göçer, 2019). Öğrenciler, Türk kültürüne ait yiyecek ve içecekler, Türk sineması ve müziği gibi ön plana çıkan kültürel unsurlar hakkında bilgi sahibi iken Türk halk oyunları ve kıyafetleri gibi detaylar hakkında bilgi sahibi olmayabilmektedir (Alyllmaz \& Onur, 2018). Ayrıca sosyal hayata yönelik kültürel unsurlara uyum sağlama hususunda Türk soylu öğrencilerin daha hızlı uyum gösterdiği, farklı kültürlerden gelen öğrencilerin uyum sürecinde daha fazla problem yaşadığı görülmüştür (Güleç \& Bekir, 2013).

Dinleme (Memiş, 2019) ile konuşma ve yazma (Şen \& İşigüzel, 2018) sürecinde yaşanan problemlerin çözümü için yabancı dil olarak Türkçe öğrenen farklı hedef kitlelere yapılan aktif öğrenme tabanlı etkinliklerin pozitif sonuçlar ortaya koyduğu belirlenmiştir. Bununla beraber dinleme, okuma, konuşma, yazma ve beşinci dil becerisi olarak kültürel becerilerin psikometrik değişkenlerle eş zamanlı ve şümullü bir şekilde geliştirilmesini sağlayan bir eğitim modeli belirlenememiştir. Mevcut çalışma yabancı dil olarak Türkçe öğrenen öğrencilerin belirtilen hususlarda pozitif yönde gelişme sağlamalarına yönelik bir model oluşmasında katkı sağlamaktadır.

\section{Teorik çerçeve}

\subsection{Sosyokültürel teori}

Vygotsky'nin sosyokültürel teorisine göre öğrenmenin en mühim amaçlarından biri de kültürü nesilden nesile aktarmaktır ve öğretmenlerin de dâhil olduğu formal ve informal iletişim süreçleri sayesinde öğrenici zihni işlemler yoluyla gelişmeler göstererek öğrenmesini tamamlar (Kozulin, 2003). Dil öğrenme süreci içinde de öğrenicinin girdiği kültür çevresi içinde gerçekleştirdiği zihni etkileşmeler ve buradan doğan tecrübeler proksimal gelişme alanını oluşturmaktadır (Lantolf, 2000). Sürecin sonunda ise öğrenici tarafından kısa süreli hafızayı ifade eden fehmetme süreci tamamlanarak uzun süreli hafızada kalıcı öğrenmenin gerçekleşmesi yoluyla idrak gerçekleşmektedir (Byrnes, 2009).

Sosyokültürel teorinin uygulama alanı bakımından potansiyeli onu yetişkin öğretiminin de bir parçası yapmış, bu yolla yetişkinlerin eğitimi ve öğretimi sürecinde yeni potansiyellerin oluşmasını sağlamıştır (Smith \& Pourchot, 2013). Nitekim yabancı dil olarak İngilizcenin öğretiminde sosyokültürel teorinin faydalı bir yaklaşım olabileceği görülmektedir (Behroozizad, Nambiar, \& Amir, 2014). Yine yabancı dil öğretimindeki motivasyon ve akademik başarı faktörünün açıklanmasında sosyokültürel faktörlerin hesaba katılması gerekmektedir (Yuanfang, 2009). Çocukların hedef kitle olarak alındığı dil öğretim sınıflarının da proksimal gelişme alanı olduğu belirlenmiştir (Fahim \& Haghani, 2012).

Yabancı dil olarak Türkçenin öğretimi alanında ise katılımcıların hedef dilin kültüründe gerçekleşen formal ve informal iletişimlerle proksimal öğrenme alanları oluşturmasına yönelik bir çalışmanın bulunmadığı ve sosyokültürel teorinin yeni bir uygulama alanı olarak potansiyel değer taşıdığı söylenebilir. Ayrıca yabancı dil olarak Türkçe öğrenen ve bu dilde acemi olan öğrencilerin dilde tecrübeli olanlarla etkileşmesi sonucunda oluşan dilde sosyalleşme (Garrett, 2008) süreci detaylı olarak incelenmemiştir. Bu sebeple çalışmada sosyokültürel teorinin temele alınmasından hareketle katılımcılara hedef dilin kültürünün ve kendi kültürlerinin eş zamanlı olarak inşa edildiği ve yeni öğrenmeleri mümkün kılan bir eğitim modelinin inşasına çalışılmıştır. 


\subsection{Araştırmanın amacı}

Araştırma boyunca farklı çalışma gruplarıyla etkili iletişim, kültürel beceriler, dört dil becerisi, yabancı dil olarak Türkçe öğrenmeye yönelik tutum, yabancı dil olarak Türkçe dil becerilerine yönelik kaygı, teknolojiyi kullanmaya yönelik beceriler ve benzeri bağımlı değişkenler nitel araştırma metotları ile derinlikli olarak incelenmiştir. Böylece çalışmada yabancı dil olarak Türkçe öğrenen ve B1 kuru ile üstündeki kurlarda eğitim gören öğrenciler için dinleme, okuma, konuşma, yazma ve 5 . dil becerisi olarak (Kramsch, 1991) kültürel becerileri geliştirecek bir modelin geliştirilmesi hedeflenmiştir. Model sadece dil becerilerinin değil katılımcıların psikometrik değişkenlerinden Türkçeye yönelik tutum ve Türkçe dil becerilerine yönelik kaygıyı da iyileştirici etkiye sahiptir.

\section{Metot}

\section{1. Çalışmanın metodu ve içeriği}

Yabancı dil olarak Türkçe öğrenen öğrencilerin dil becerilerinde ve psikolojik değişkenlerinde sahip oldukları problemlerin iyileştirilmesi için bir model inşa edilmesi bu çalışmanın ana amacını oluş̧urmaktadır. Bu sebeple iyileştirme süreci için bir aksiyon araştırmasının yürütülmesine (Yıldırım \& Şimşek, 2016), modelin oluşturulabilmesinde gerekli uygulama aşamalarının belirlenmesi için de aksiyon araştırması türlerinden uygulama odaklı aksiyon araştırmasının (Creswell, 2012) kullanılmasına karar verilmiştir.

Çalışma 2 yıllık araştırma süreci boyunca farklı çalışma gruplarında araştırmacılar tarafından yapılan gözlem ve görüşme çalışmaları ile araştırmacı günlüklerine dayanmaktadır. İlk olarak yabancı dil olarak Türkçe öğrenen öğrencilerin kültürel becerilerinin ve dil becerilerinin gelişmesi sürecinde problemler yaşadıklarına dair veriler araştırmacı günlükleri ile elde edilmiştir. Verilerin altında yatan kategorilerin ortaya çıarılması için açık kodlama (Corbin \& Strauss, 1990) ile analizler tamamlanmıştır. Elde edilen bulgular sürecin paydaşları olan öğretmenler ve öğrencilerden daha derinlikli veri alınması gerektiğini ortaya koymuştur. Böylece 2016-2017 eğitim-öğretim yılı içerisinde önce öğretmenlerden oluşan katılımcılarla kültür aktarımı üzerine görüşme çalışması yapılmıştır. Buradan hareketle öğrencilerden oluşan iki ayrı grupla etkili iletişim becerileri ile kültür aktarımı hususlarında derinlikli görüşmeler gerçekleştirilmiştir. Görüşme verilerinin belli bir yönüne odaklanılması, sistematik bir analiz yapılması ve gerektiğinde araştırmanın nicel formu ile mukayese edilebilir olması için içerik analizi ile (Schreier, 2014) bulgulaştırılmasına karar verilmiştir.

Elde edilen bulgular neticesinde öğrencilerin yabancı dil olarak Türkçe dil becerilerinin ve dil becerilerini etkileyen psikolojik değişkenlerin iyileştirilmesi için araştırmanın aksiyon planı oluşturulmuştur: 


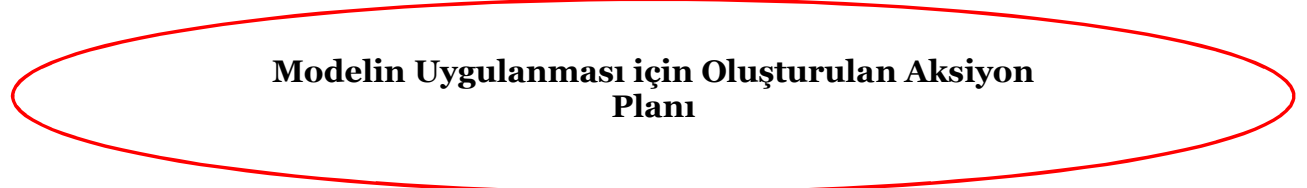

1. Hazırlık: Elde edilen nitel bulgular, Avrupa Dil Portfolyosu ve literatür taraması sonucunda olușturulan problem cümlelerine uzman görüșü alınarak son șeklinin verilmesi

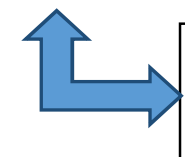

2. Uygulama Modelinin Planlanması: Eğitim modelinin pilot uygulamasının yapılması sonucu gözlem, araştırmacı günlükleri ve görüşmeler yoluyla öğrencilerin yaşadıkları problemlerin belirlenmesi

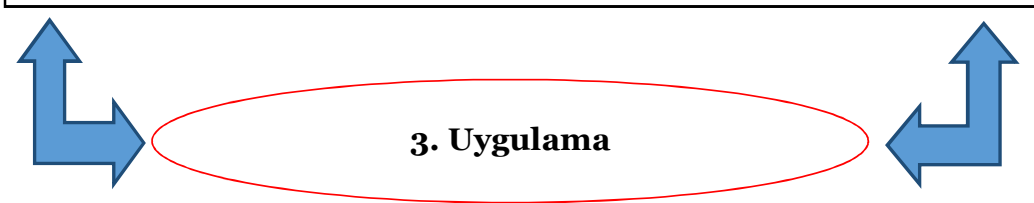

3.1. Pilot Uygulama

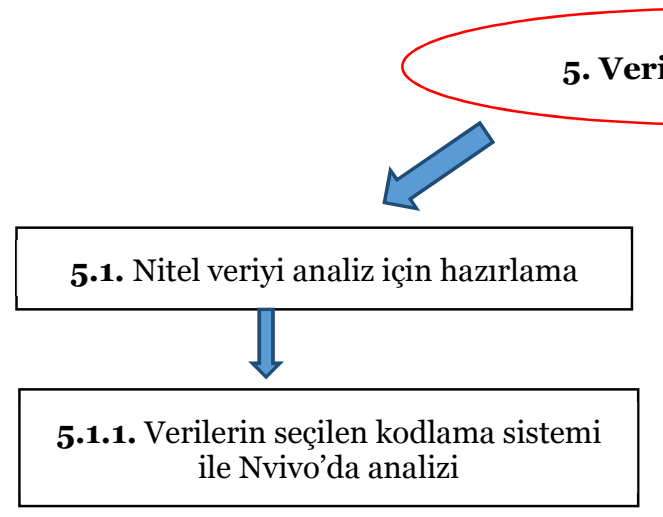

3.2. Gözden Geçirme ve Yeniden Planlama

1. Şekil: Modelin inşa süreci.

Elde edilen bulgular neticesinde B2 seviyesinde yabancı dil olarak Türkçe öğrenen katılımcılarla ilk Kültür Günleri etkinliği düzenlenmiş ve her öğrencinin kendi ülkesini hazırlayacağı sunumla tanıtması istenmiştir. Buna ek olarak stant faaliyetleri düzenlenerek öğrencilerin yazma, hazırlıklı ve hazırlıksız konuşma, dinleme, okuma becerilerinin geliştirilmesi ve psikolojik özelliklerine pozitif katkı sağlaması

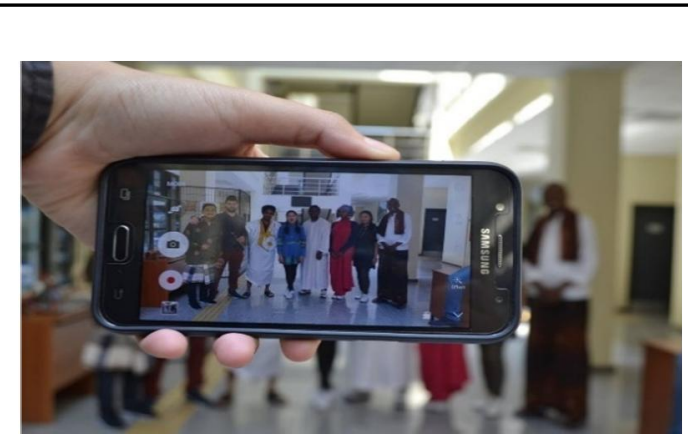

of Arts and Sciences, Department of ure, Kayalı Campus-Kırklareli/TURKEY 
hedeflenmiştir.

2016-2017 eğitim-öğretim yılının ilk Kültür Günleri için katılımcılarla yapılan görüşmeler neticesinde etkinliğe yönelik pozitif tutum geliştirildiği, bununla birlikte hedeflenen kazanımlara ulaşılması için etkinliğin daha uzun bir sürece yayılması gerektiği görüşleri alınmıştır.

Bunun üzerine gözden geçirme ve yeniden planlama safhasına geçilmiş ve 2017-2018 eğitim-öğretim yllında uygulanmak üzere mentorluk sürecinin inşasına başlanmıştır. Mentorluk sisteminde yabancı dil olarak Türkçe öğretiminin aynı zamanda bir kültür aktarımı olmasından (Barın, 2004) hareketle öğrencilere hem dört dil becerisinde hem de çift yönlü kültür aktarımının sağlanması için Türkçe öğretmeni adayları ile yabancı dil olarak Türkçe öğrenen öğrencilerin eşleştirilmesi sağlanmıştır. Mentorların seçiminde ise sınıf seviyesi ve Yabancılara Türkçe Öğretimi dersinin alınmış olması kriteri gözetilmiş (Şahin, Kurudayığlu, Tunçel, \& Öztürk, 2013), 3. sınıf ve üstü Türkçe öğretmeni adayları mentor olarak seçilmiştir. Sonrasında Kültür Günleri için 10 haftalık hazırlık sürecine geçilmiş, bu süreç içinde düzenli olarak haftalık etkinlikler yapılmıştır. Süreçte mentorlar katılımcılara rehberlik vazifesini üstlenmiş, Kültür Günleri’ne hazırlanmalarında destekleyici rol almıştır. Yapılan düzenlemelere göre modelin son şekli şudur:

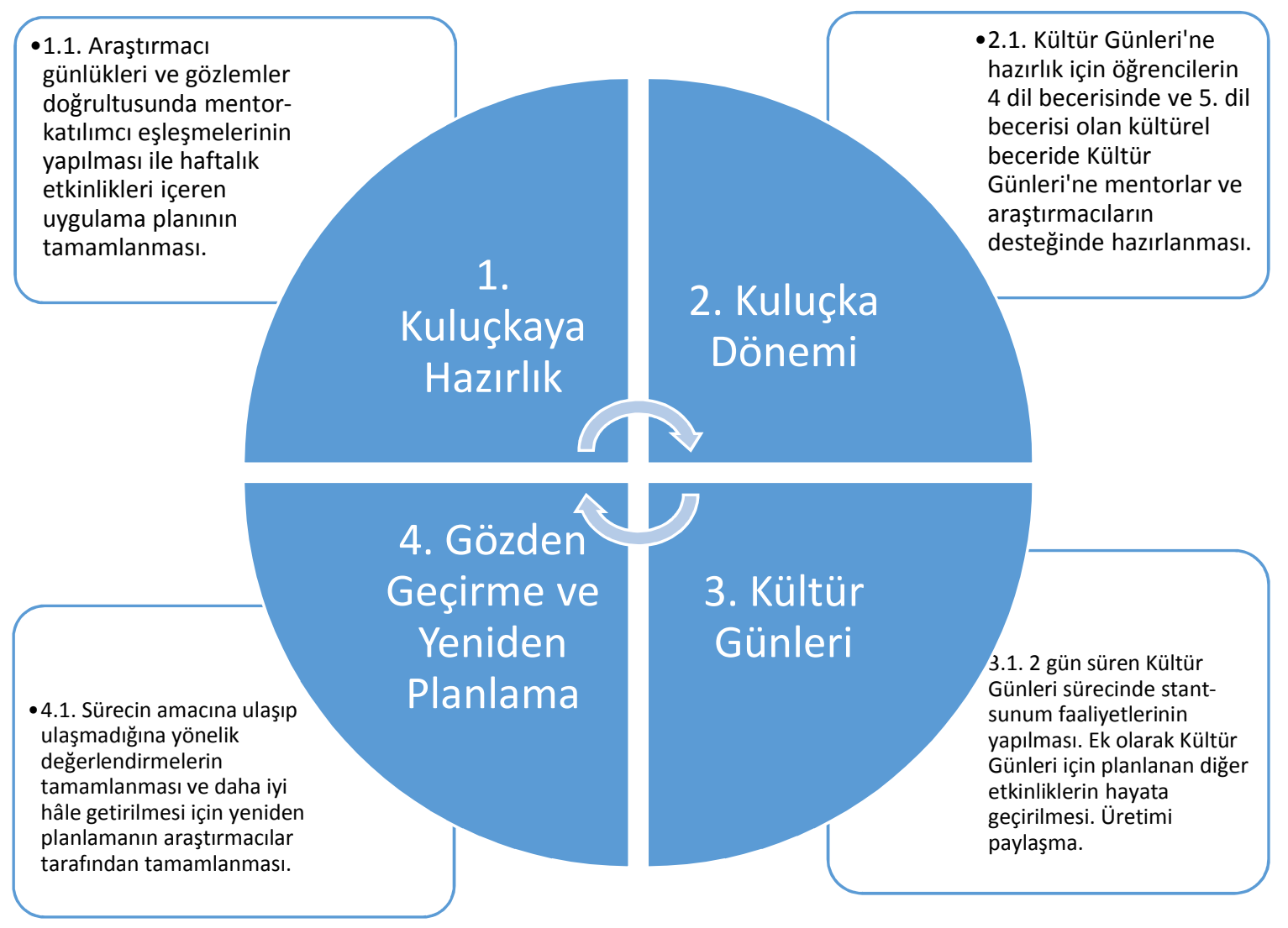

2. Şekil: Kültür günleri modeli

\subsection{Veri toplama}

Araştırma verilerinin toplanmasında sınırlı çalışma grupları üzerinde çalışılması, araştırmanın ekonomik, etkili ve verimli bir şekilde çalışılması, ayrıca derinlikli ve güvenilir veri elde edilmesi 
54 / RumeliDE Journal of Language and Literature Studies 2020.19 (June)

A new model in teaching Turkish as a foreign language: Culture Days / E. Yazıcı; T. Göktentürk (pp. 48-77)

amacıyla üçgenleme metodu (Creswell, 2012; Silverman, 2013; Yıldırım \& Şimşek, 2016) kullanılarak yarı yapılandırılmış görüşme, gözlem ve araştırmacı günlüğ̈̈ ile veriler toplanmıştır. Uygulanma zamanları, katılımcı sayısı ve hedef kitle bakımından veri toplama süreci şu şekildedir: 
1. Tablo: Veri toplama araçlarının yıllara göre kullanımı

\begin{tabular}{|c|c|c|c|c|c|c|}
\hline & \multicolumn{3}{|c|}{ 2016-2017 } & \multicolumn{3}{|c|}{$2017-2018$} \\
\hline & Hedef Kitle & $\begin{array}{l}\text { Katılımcı } \\
\text { Sayısı }\end{array}$ & $\begin{array}{l}\text { Araştırma } \\
\text { Konusu }\end{array}$ & Hedef Kitle & $\begin{array}{c}\text { Katılıme } \\
\text { Sayısı }\end{array}$ & $\begin{array}{c}\text { Araştırma } \\
\text { Konusu }\end{array}$ \\
\hline \multirow[t]{3}{*}{ Görüşme } & $\begin{array}{l}\text { Yabancı dil } \\
\text { olarak } \\
\text { Türkçe } \\
\text { öğrenen C1 } \\
\text { seviyesindeki } \\
\text { ögrenciler }\end{array}$ & 7 & $\begin{array}{l}\text { Kültür } \\
\text { aktarımı }\end{array}$ & $\begin{array}{l}\text { Türkçe } \\
\text { Öğretmeni } \\
\text { Adayları }\end{array}$ & 6 & $\begin{array}{c}\text { Kültür } \\
\text { Günleri } \\
\text { hakkında } \\
\text { görüsslerinin } \\
\text { belirlenmesi }\end{array}$ \\
\hline & $\begin{array}{c}\text { Yabancı dil } \\
\text { olarak } \\
\text { Türkçe } \\
\text { öğreten } \\
\text { öğretmenler }\end{array}$ & 6 & $\begin{array}{c}\text { Kültür } \\
\text { Aktarımı }\end{array}$ & $\begin{array}{l}\text { Yabancı dil } \\
\text { olarak } \\
\text { Türkçe } \\
\text { öğrenen C1 } \\
\text { seviyesindeki } \\
\text { öğrenciler }\end{array}$ & 20 & $\begin{array}{c}\text { Kültür } \\
\text { Günleri } \\
\text { hakkında } \\
\text { görüşlerinin } \\
\text { belirlenmesi }\end{array}$ \\
\hline & $\begin{array}{c}\text { Yabancı dil } \\
\text { olarak } \\
\text { Türkçe } \\
\text { öğrenen B2 } \\
\text { seviyesindeki } \\
\text { öğrenciler }\end{array}$ & 8 & $\begin{array}{c}\text { Etkili } \\
\text { Konuşma }\end{array}$ & & & \\
\hline \multirow[t]{2}{*}{ Gözlem } & $\begin{array}{l}\text { Yabancı dil } \\
\text { olarak } \\
\text { Türkçe } \\
\text { öğrenen } \\
\text { katılımcılar }\end{array}$ & 18 & $\begin{array}{l}4 \text { dil becerisi } \\
\text { ve kültürel } \\
\text { beceriler ile } \\
\text { psikolojik } \\
\text { süreç }\end{array}$ & $\begin{array}{c}\text { Yabancı dil } \\
\text { olarak } \\
\text { Türkçe } \\
\text { öğrenen } \\
\text { katılımcılar }\end{array}$ & 33 & $\begin{array}{l}4 \text { dil becerisi, } \\
\text { kültürel } \\
\text { beceriler ve } \\
\text { psikolojik } \\
\text { süreç }\end{array}$ \\
\hline & & & & Mentorlar & 14 & $\begin{array}{c}\text { Öğretmenlik } \\
\text { becerileri ve } \\
\text { psikolojik } \\
\text { süreç }\end{array}$ \\
\hline \multirow[t]{2}{*}{$\begin{array}{l}\text { Araştırmacı } \\
\text { Gǘnlüğü }\end{array}$} & $\begin{array}{l}\text { Yabancı dil } \\
\text { olarak } \\
\text { Türkçe } \\
\text { öğrenen } \\
\text { katılımcılar }\end{array}$ & 18 & & $\begin{array}{l}\text { Yabancı dil } \\
\text { olarak } \\
\text { Türkçe } \\
\text { öğrenen } \\
\text { katılımcılar }\end{array}$ & 33 & $\begin{array}{l}4 \text { dil becerisi, } \\
\text { kültürel } \\
\text { beceriler ve } \\
\text { psikolojik } \\
\text { süreç }\end{array}$ \\
\hline & & & & Mentorlar & 14 & $\begin{array}{l}\text { Ö̈̆retmenlik } \\
\text { becerileri ve } \\
\text { psikolojik } \\
\text { süreç }\end{array}$ \\
\hline
\end{tabular}

2016-2017 ylındaki yarı yapılandırılmış görüşme formları ile gerçekleştirilen görüşme çalışmaları odak grup görüşmesi şeklindedir. Görüşmeler ses kayıt cihazları ile kayıt altına alınmış ve NVivo programında içerik analizi ile çözülmüştür. 2017-2018 döneminde ise mentorlardan oluşan Türkçe öğretmeni adayları ile birebir görüşmeler yapılmıştır. Odak grup görüşmesine karar verilen yabancı dil olarak Türkçe öğrenen katılımcılardan ise, sayının artmasının görüşmenin kalitesini düşürebileceği düşüncesiyle, 10’ar kişilik iki ayrı grup hâlinde veri toplanmıştır. Görüşme süreçlerinin tamamında çalışma grubunu belirlerken katılmaya istekli olma şartı koşulmuş ve bunun için amaçlı örnekleme metotlarından kriterli örnekleme kullanıştır (Yıldırım \& Şimşek, 2016).

Gözlem sürecinde ise öğrencileri tabii hâlinde gözleyerek veri elde etmek amacıyla yapılandırılmamış gözlem kullanılmıştır (Yıldırım \& Şimşek, 2016). Bu yolla katılımcılardan daha geniş ve derinlikli veri elde edileceği düşünülmüş, ayrıca araştırmacılar tarafından gözden kaçırılabilecek unsurların 
araştırma verilerine dâhil edilmesi hedeflenmiştir. Araştırmacı günlükleri de aynı sebepten yapılandırılmamış şekilde tutulmuştur.

Araştırmada verilerin güvenilirliği ve üçgenleme farklı hedef kitlelerden elde edilen verilerin mukayeseli şekilde incelenmesi ile sağlanmıştır. İçerik analizi ve açık kodlama kullanılarak elde edilmiş olan kategoriler incelenmiş ve birbirleri ile tutarlı olup olmadıkları göz önünde bulundurulmuştur (Corbin \& Strauss, 1990). Ayrıca araştırma sonunda elde edilen görüssme verilerinin güvenilirliğinin belirlenmesi için Miles and Huberman (1994) tarafından geliştirilmiş olan formülden faydalanılmıştır.

\section{Bulgular}

Araştırma bulguları oluşan temalar doğrultusunda tarif ve tasnif edilmiştir. Veriler ana başlığında kronolojik olarak temalanmış ve bu yolla Kültür Günleri'ni oluşturan veri havuzunun ve Kültür Günleri'nin faaliyete geçirilmesi sonucu oluşan veri havuzunun daha anlaşılır ve derinlikli olarak izah edilmesi hedeflenmiştir.

\subsection{6-2017 verilerinden elde edilen temalar}

Bu başlık altında sunulan temalar görüşme gözlem ve araştırmacı günlüklerinin mukayeseli olarak incelenmesi ve raporlaştırılması sonucunda elde edilmiştir.

\subsubsection{Kültür aktarımı}

2016-2017 eğitim-öğretim yılında görüşme yapılan 7 katılımcıdan elde edilen veriler kendi seviyelerine uygun hızda eğitimin verilmesini istemiştir. Uygun hızda eğitimin yapılandırılmasının yanında tarihi bağın kültür aktarımı için mühim olduğu belirtilmiştir. Bu husus katılımcılardan elde edilen şu ifadede görülmektedir: "Türk kültürünü ve Türk dilin öğrenirken önümüzdeki bilinmeyen kelimelerin anlamların tanımak için tarihe bakıyoruz. Tarihe bakarken hem Türk kültürünü hem Türk dilin öğreniyoruz.".

Ek olarak ders kitaplarında Türk kültürünün kapladığı alanın artması ve daha detaylı olması, ayrıca kültürel becerilerin geliştirilmesi için kültürel unsurlar hakkında bilgi sahibi olmanın gerekliliği belirtilmiştir. Bu noktada öğretim süreci içinde günlük hayata ait unsurlara yer verilmesinin faydalı olduğu, Türk romanları, Türk tiyatrosu ve filmleri gibi materyallerin kullanılmasının faydalı olduğu sonucuna varılmıştır.

Yabancı dil olarak Türkçe öğreten hocalarla yapılan görüşmelerden elde edilen verilerin analizi neticesinde ise kültürel unsurların derslerde işlenmesi öğrencilerin öğrenme motivasyonunu artırmaktadır. Ayrıca bilginin kahıclığı, somutlaştırma sağlaması, öğrenme sürecine adaptasyonu temin etmesi, iletişim becerilerini geliştirmesi bakımından da kültürel unsurlar faydalı görülmektedir.

\subsection{2. Öğrenme sürecinin içeriği}

Hocalarla ve öğrencilerle yapılan görüşmelerde ders anlatımında siyasi konulara yer verilmemesi bütün katılımcıların ortak görüşü olarak ön plana çıkmaktadır. Bu hususu katılımcılardan elde edilen şu ifadede görmek mümkündür: "Siyasi ve politik konuların dâhil edilmesi her öğrencinin ortak 
görüşünü yansıtmayacağından motivasyonu düşürebilmekte, ayrıca negatif bir tutum doğurabilmektedir.”.

Ders kitapları başta olmak üzere öğretim sürecinin tamamında öğrencilerin ihtiyactna uygun ve günlük hayatı yansıtan içeriğin seçilmesi de faydalı görülmektedir. Türk kültüründen ziyade Türkçe kültürü üzerinde durulması, yani kültürün dil öğrenimi ile münasebetinin kurulması gerekmektedir. Hocalardan elde edilen görüşler öğrencilerin öğrenme süreci sonunda hayatta karşılaşacakları iş görüşmesi, ticaret kültürü gibi bilgilere de yer verilmesi gerektiğine yönelik bulgular ortaya koymuştur. Son olarak değer öğretimi hususunda beynelmilel bir sınıf yapısına uygun olacak şekilde ortak kültür öğeleri, ortak kelimeler ve ortak sanat eserlerinin de içeriğe dâhil edilmesi katılımcılar bakımından faydalı görülmektedir. Bu husus katılımcılardan edinilen şu ifadede görülmektedir: "Öğrenci, kaynakta kendi dilinden bir kelime ile ve kültürle karşılaştığında daha mutlu ve daha huzurlu olur kendini Türkçeye ait hissetmeye başlar.”.

\title{
4.1.3. Dört dil becerisi
}

Bu tema araştırmacı günlükleri ve gözlem kayıtlarının analizi sonucunda elde edilmiştir. Dört dil becerisinin geliştirilmesi hususunda mevcut öğretim sürecinin katkı sağladığı ancak mevcut eksiklerin giderilmesi hâlinde çok daha etkili ve verimli bir öğrenme sürecinin gerçekleşebileceği araştırmacı günlüklerinde şu şekilde kendisine yer bulmuştur:

\begin{abstract}
“Öğrencilerin öğrenme süreçleri çoklukla kullandığımız sete bağlı. Öğrenci farklı bir kaynak bulmak istediğinde ders kitabı yanında çalışma kitabına yönelebiliyor. İnternetten buldukları kaynaklar yahut filmler ise farklı dil becerilerini öğrenmek için ellerindeki şanslardan bazıları. Süreci daha verimli hâle getirmek istiyorsak öncelikle dört dil becerisini daha zengin bir içerikle sunacak bir sürece ihtiyacımız var. Ayrıca öğrenciler öğrendiği dil becerilerini sadece günlük hayat için kullanıyorlar; hâlbuki gelecek sene akademik Türkçe görecekler ve programda buna uygun bir uygulama veya tedbir henüz yok.” (2017 Nisan 20 Perşembe, Araştırmacı Günlüğü)
\end{abstract}

Gözlemler sırasında öğrencilerin sadece kitaba dayah olarak 4 dil becerisini öğrendiği, kitap ile oluşturulan ana çerçevenin geliştirilmesi için uyarı zenginliğinin sağlanması ve kalıcı öğrenmenin sağlanması için öğrencilerin aktif olması prensibine dayanan aktif öğrenme (Açıgöz, 2003) temelli etkinliklerinin kullanılmasının faydalı olabileceği tespit edilmiştir.

\subsubsection{Gramer becerileri}

Ders içindeki gözlemler ve ders sonrası tutulan araştırmacı günlükleri neticesinde öğrencilerin gramer yapılarının fonksiyonel yönünü kavramaları hususunda problemler ortaya konmuştur. Ayrıca ders içindeki etkinlik sürecinin daha da fazlalaşması hâlinde kalıcı öğrenmenin gerçekleşeceği ve gramer becerilerinde ciddi gelişmeler görülebileceğine yönelik bulgular tespit edilmiştir. Gözlem ve araştırmacı günlüklerine ortak metin olarak geçen şu ifadeler belirtilen bulgulara işaret etmektedir:

"Öğrenciler ders içinde konuşmak, espri yapmak, zihnindeki karmaşık düşünceleri ana dillerinde olduğu gibi izah etmek istiyor; ama gramer becerileri hususunda sıkıntı yaşayan bazı öğrencilerin anlamlı bir iletişim kurması hakikaten güç. Ders içinde onları aktifleştirecek daha fazla etkinlik bulmalıyım. Sadece okuma becerisi derslerine girmek beni kısıtlamamalı. Ayrıca gramatikal farklara yönelik doğru geri bildirimleri verebilmeliyim. Öğrencilerin dil becerilerini kullanabilecekleri yeni alanları bulmaları ise kalıı öğrenmeyi sağlayabilir.” (2017 Şubat 16 Perşembe, Araştırmacı Günlüğü - Gözlem Kaydı) 
İfade aynı zamanda gramer becerilerinin geri bildirim yoluyla geliştirilmesine işaret etmektedir. Derslerde anlatım becerilerinden daha çok konuşma kullanılmıştır. Katılımcılar ise gramer becerilerinde problem yaşamaktadır.

\title{
4.1.5. Yabancı dil olarak Türkçe öğrenmeye yönelik tutum
}

Öğrencilerin Türkçe öğrenmeye yönelik pozitif tutum sergilediği ve Türkçe öğrenme sürecinde Türk kültürüne ait unsurlar görmekten hoşlandığına yönelik araştırmacı günlüklerinde ve gözlemlerde veriler elde edilmiştir. Bu hususta öğrencilerin tutumu pozitif yöndedir.

\subsubsection{Yabancı dil olarak Türkçe öğrenmeye yönelik kaygı}

Öğrencilerin genelinde yabancı dil olarak Türkçe öğrenmeye yönelik yüksek seviye kaygı görülmemekle beraber dil becerilerini geliştirme hususunda problem yaşayan öğrencilerde yüksek seviye kaygının olduğuna dair bulgular elde edilmiştir. Ayrıca belli seviyeye kadar kaygı da öğrenme için faydalıdır. İlgili bulgular şu ifadede görülmektedir:

“Öğrencilerden ders içinde motivasyonlu bir şekilde katılım gösterenler genellikle dil becerileri iyi olan öğrenciler. Gerekli gelişimi gösterememiş öğrencilerde derse katılmak inanılmaz bir kaygı oluşturuyor ve bazı öğrenciler mecbur olmasa Türkçe öğrenmek istemediklerini davranışları ile belirtiyorlar. Belli bir seviyeye kadar olan kaygı ise verilen vazifelerin tamamlanmasında motivasyon kaynağı olarak fayda sağlıyor.” (2017 Nisan 27 Perşembe, Gözlem Kaydı)

\begin{abstract}
"Kaygıyı yenmek için yapılabilecek çok sayıda şey var; ama bence bu öğrencilerin bilgi seviyesi ve dil becerilerinin gelişmişliği ile doğrudan alakalı. Zararlı kaygıları ortadan kaldırmak için mutlaka notun ve bursu kaybetmenin yarattığı baskı en aza indirilmeli. Ayrıca öğrencilere dil yapıları arasındaki farkları öğretmek için daha fazla geri bildirim verilmeli. Geçen bir öğrencim "geldiyse" ile "gelseydi" farkını sordu. "geldi i-se" ifadesinde zaman "gelse i-di" ifadesinde ise şart mühimdir şeklinde açıkladım. Bu gibi farkları rahat anladığında öğrencide kalıcı öğrenme gerçekleşiyor ve kabul edilebilir seviyenin üstünde kaygı oluşmuyor." (2017 Mart 25 Cumartesi, Araştırmacı Günlüğü)
\end{abstract}

\subsection{7. Öz yeterlilik algıSı}

Öğrencilerin öz yeterlilik algısı seviye ilerledikçe artmakta, bilhassa B2 seviyesinde iyi seviyelere ulaşmaktadır. Bununla birlikte $\mathrm{C} 1$ seviyesi sonrası akademik dilin kullanılacağı lisans eğitiminin oluşturduğu kaygı sebebiyle bazı öğrencilerde kısmi olarak öz yeterlilik algılarında düşüş görülmektedir. Bununla ilgili araştırmacı günlüğü şu şekildedir.

“C1 seviyesinde mezun olan öğrencilerimizden ziyaretime gelenlerle bugün görüştüm. Öğrenciler TÖMER'de aldıkları eğitimin günlük hayat için yeterli; ancak akademik Türkçe için ise yetersiz olduğunu söylediler. Öğrencilerin bu problemleri yaşamasının sebebi henüz akademik seviyede sunum yapmamış yahut akademik Türkçeye yeterince maruz kalmamış olmaları olarak söylenebilir.” (2017 Eylül 18 Pazartesi, Araştırmacı Günlüğü)

\subsection{7-2018 verilerinden elde edilen temalar}

2016-2017 verilerinden hareketle geliştirilen ve planlaması tamamlanan Kültür Günleri modelinin uygulanma süreci ve sonucuna dair görüşme verileri içerik analizi ile incelenmiş, elde edilen temalar ve alt kategorileri araştırmacı günlüğü ve gözlemlerden elde edilen bulgularla mukayeseli olarak sunulmuştur. Uygulama safhasının mentorlar ve yabancı dil olarak Türkçe öğrenenler tarafından katılımcılarının oluşturulması sebebiyle veriler bu iki hedef kitlenin gözünden incelenmiştir. 


\subsubsection{Yabancı dil olarak Türkçe öğrenen öğrencilere ait Kültür Günleri bulguları}

Bu başlık altın Kültür Günleri sonrasında yapılan görüşmelerden elde edilen verilerin gözlem ve araştırmacı günlükleri ile mukayeseli olarak incelenmesinden elde edilen temalar verilmiştir.

\subsubsection{Dinleme becerisi}

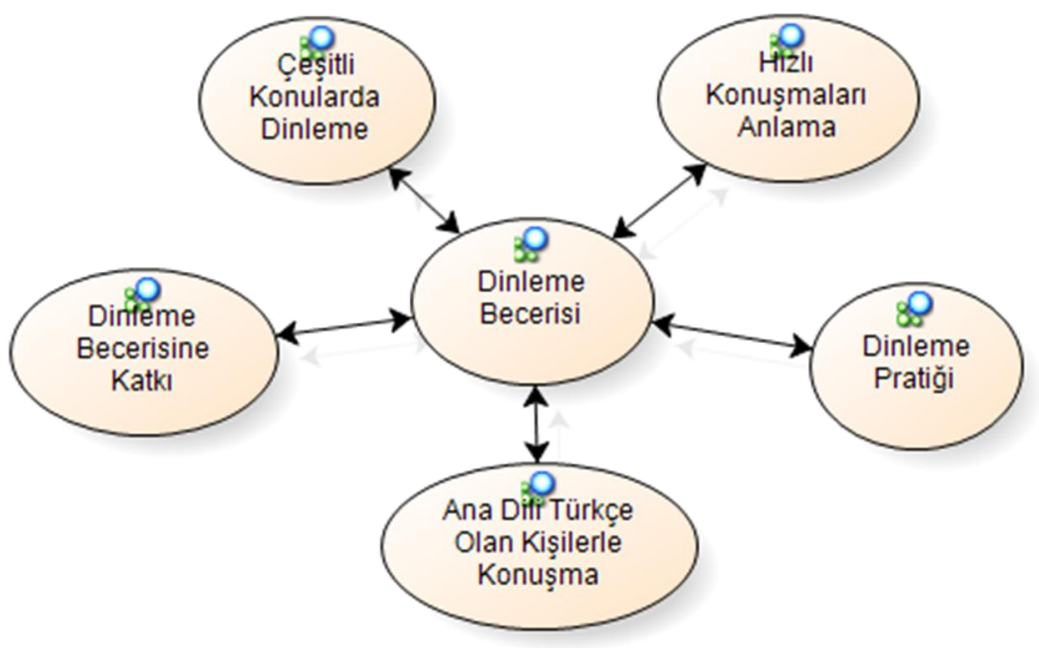

3. Şekil: Dinleme becerisinin geliştirilmesine yönelik Kültür Günleri alt modeli

Dinleme becerisinin geliştirilmesine yönelik olarak öğrencilerle yapılan görüşmelerden elde edilen bulgular öğrencilerin Kültür Günleri sayesinde farklı konuları dinlerken zorlanmadıklarını göstermektedir. Dinleme becerileri süreç sayesinde gelişmiş ve ana dili Türkçe olan kişileri dinlerken yaşadıkları problemleri aşmaları mümkün olmuştur. Ayrıca hem mentorluk süreci hem de stant ve sunum faaliyetleri ile yapılan diğer etkinlikler dinleme pratiği yapmak için imkân sunmuştur. Son olarak Kültür Günleri’nin hızlı konuşmalarda bile öğrencilerin anlayabilecek seviyeye gelmeyi sağladığı görülmektedir.

Araştırmacı günlükleri ve gözlem verilerinin de paralel veriler sunduğu görülmektedir. Bu veri kaynaklarından elde edilen bulgular öğrencilerin dinleme becerilerine yönelik aşağıdaki ifadeler süreçte hem mentorlar hem etkinlikler yoluyla ana dili Türkçe olanlarla yapılan konuşmaların dinleme becerisine katkı sağladığını desteklemektir. Ayrıca süreç boyunca sunum hazırlığı ve araştırma sürecinde yapllan dinlemeler dinleme becerisine pozitif etki etmiştir:

“Kültür Günleri’nin sonuna geldik. Öğrenciler için süreç gerçekten çok faydalı oldu. Bütün süreç boyunca sadece Türkçe ile iletişim kurmaları ve hedef dile maruz kalmaları dinleme becerilerinde ciddi manada pozitif katkı sağlamış görünüyor. "Hocam çok hızlı konuşuyorsunuz.” sözünü artık duymuyorum. (2)" (2018 Mayıs 10 Perşembe, Araştırmacı Günlüğü)

"Yemen sunumu devam ediyor. Kültürel alanda yapılan sunumların şu faydası da ortaya çımakta. Öğrencilerin Türkçe üzerine dinleme becerilerinin sadece günlük hayat ifadelerinde değil aynı zamanda kültürel noktada o dile has ifadeleri öğrenme bakımından da gelişiyor.” (2018 Mayıs 9 Çarşamba, Gözlem Kayıtları) 


\subsubsection{Konuşma becerisi}

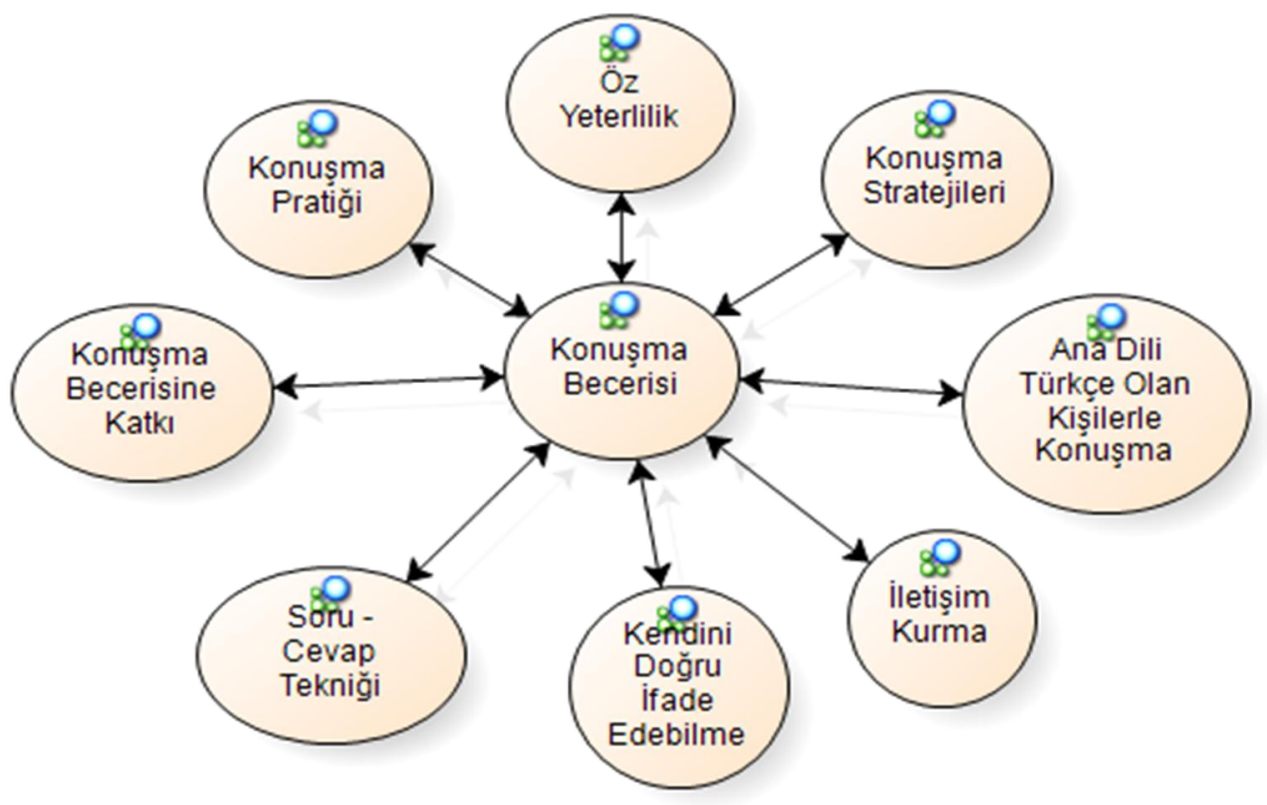

4. Şekil: Konuşma becerisinin geliştirilmesine yönelik Kültür Günleri alt modeli

Katılımcıların konuşma becerisinin geliştiği ve Kültür Günleri’nin bu hususta fayda sağladığı görülmektedir. Bilhassa ana dili Türkçe olan kişilerle konuşmanın bu noktada katkı sağladığı belirlenmiştir. Öğrenciler süreç boyunca konuşma pratiği yapma imkânı bulmuş, konuşma öz yeterlilik algılarını pozitif yönde geliştirmiştir. Konuşma stratejilerini kullanmaya yönelik öz yeterlilikleri de pozitif ilerleme göstermiştir. Konuşmanın meyanına uygun olarak kendini doğru ifade edebilmeleri sağlanmıştır. Bütün bu gelişmelerde ise ana dili Türkçe olanlarla iletişim kurmaları, düzenli olarak Kültür Günleri’nde gerçekleşen stant ve sunum faaliyetlerinde ülkeleri hakkındaki soruları cevaplamaları katkı sağlamıştır. Araştırmacı günlüklerinden elde edilen verilerin de elde edilen bulgularla örtüştüğü görülmektedir:

“Öğrenciler hiç olmadığı kadar konuşmaya istekli. Tamamen aktifler, stantta sorulan sorulara cevap veriyorlar, konuşma noktasında çekinen ise yok. Abdülcelil'in, Nijeryalı öğrencim, sunumu bu noktada harikaydı. Onu dinleyenler yaptığı espriler ve sunum tarzından ciddi manada eğlenerek çıktılar. Öğrencilerin ana dili Türkçe olan insanları kendileri için yabancı olan bir dilde eğlendirebilmeleri artık B2 seviyesinde olan öğrencilere göre dile hâkim olduklarını gösteriyor. Kültür Günleri’nin konuşma becerilerinin gelişmesini hızlandırdığını görüyoruz.” (2018 Mayıs 9 Çarşamba, Araştırmacı Günlüğü) 


\subsubsection{Okuma becerisi}

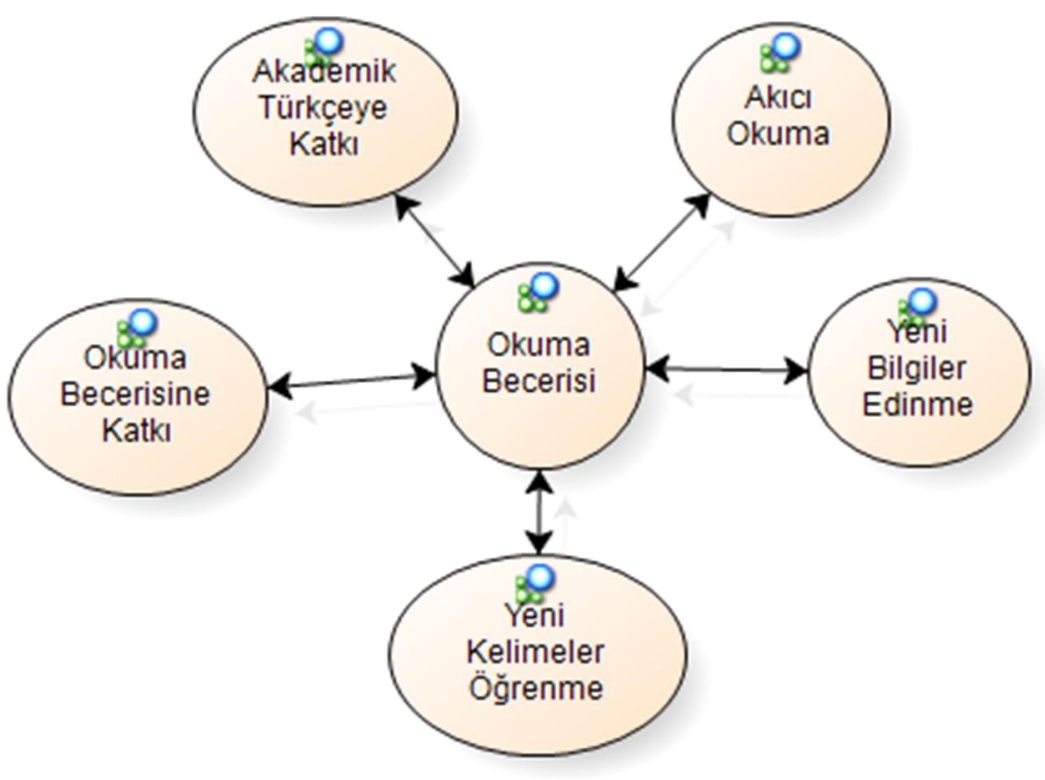

5. Şekil: Okuma becerisinin geliştirilmesine yönelik Kültür Günleri alt modeli

Kültür Günleri’ne hazırlık sürecinde yapılan okumaların öğrencilere katkı sağladığı görüşmeden elde edilen bulgularda görülmektedir. Yapılan akademik metin okumaları akademik Türkçe metinleri okuma becerisini geliştirmiş, ayrıca mentorlarla yapılan tavsiyeleşmeler ve sunuma hazırlık için yapılan akademik olmayan metinleri okuma edebiyat, kültür, sanat, blog ve benzeri Türkçe metinleri daha sık okumayı sağlamıştır. Yapılan okumalar akıcı okumayı sağlarken yeni kelimeler öğrenmeyi ve yeni bilgiler öğrenmeyi de temin etmiştir. Bu noktada gözlem kayıtlarında şu ifadelere yer verilmiştir:

"Ders içinde öğrencilere kitaplar üzerine Dil Atölyesi bünyesinde etkinlikler düzenlediğimizden bahsedildi. Ders içinde öğrenciler seviyelerine uygun kitap bulma noktasında mentorlarından da kaynak tavsiyesi alabildiklerini, Kültür Günleri’ne hazırlık için de okuma yapmayı sürdürdüklerini belirttiler. Bu çalışmalar okuma becerilerinin geliştirilmesinde katkı sağlayacaktır.” (2018 Nisan 10 Salı, Gözlem Kayıtları) 


\subsubsection{Yazma becerisi}

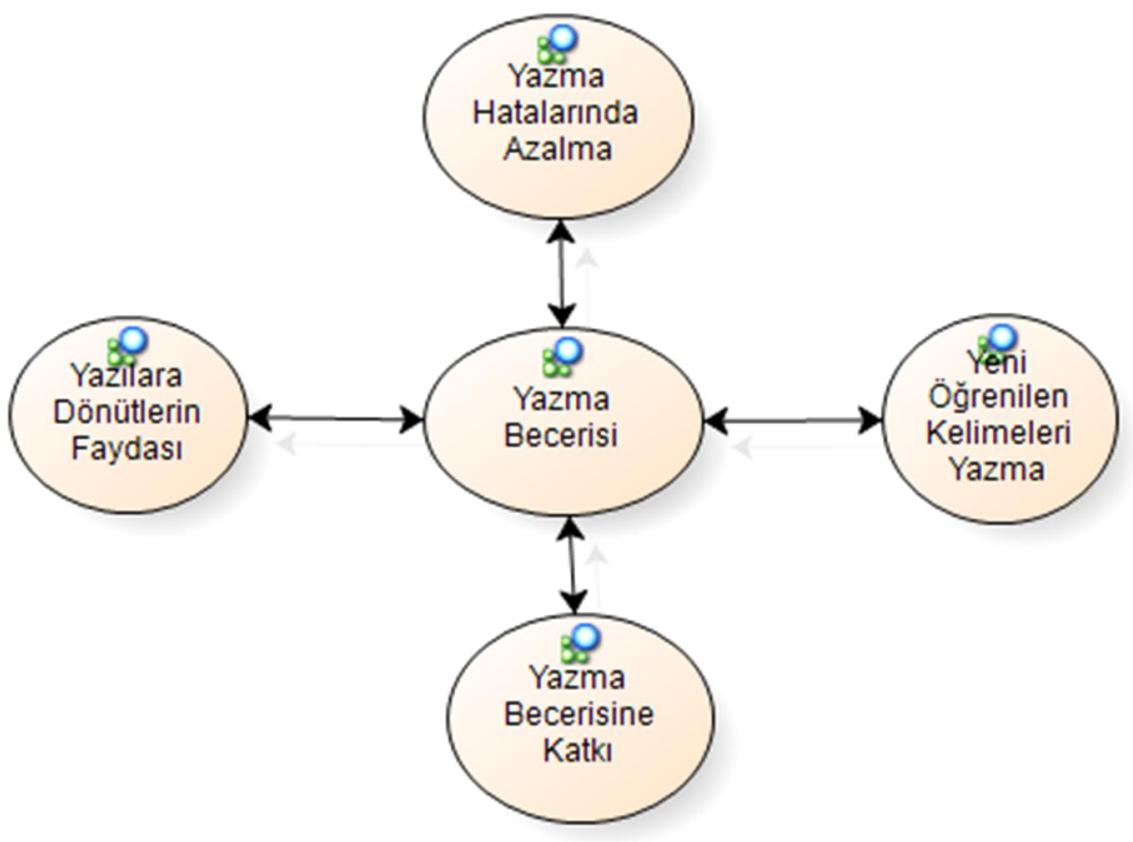

6. Şekil: Yazma becerisinin geliştirilmesine yönelik Kültür Günleri alt modeli

Öğrencilerin yazma becerilerinin gelişiminin sunum hazırlığı, yani kuluçka dönemi sayesinde olduğu görülmektedir. Sunum hazırlama sürecinde hem konuşma metinleri hem de sunum dosyaları için metinler hazırlayan öğrenciler düzenli olarak bu husus hakkında dönütler almıştır. Böylece yazma hatalarında azalma sağlanmış, yeni öğrenilen kelimelerin yazılarda kullanılması ile aktif söz varlıkları gelişmiştir. Kültür Günleri’nin bu yönüyle yazma becerisine katkı sağladığı görülmektedir.

\subsubsection{Kültür aktarımı}

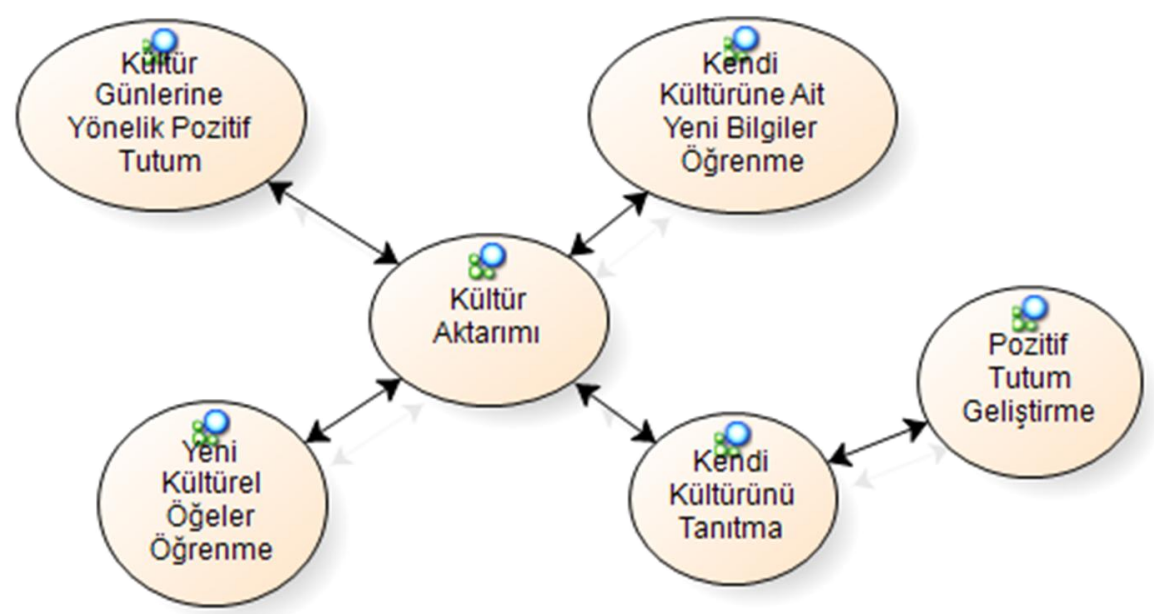

7. Şekil: Kültür aktarımına yönelik Kültür Günleri alt modeli 
Katılımcılarla yapılan görüşmelerle elde edilen bulgular kendi kültürlerini tanıtmaya ve kendi kültürlerine yönelik öğrencilerin pozitif tutumlarının geliştiğini göstermektedir. Süreç boyunca Kültür Günleri’ne hazırlık için yapılan araştırmalar ve bilgi toplama sürecinin kendi kültürlerine yönelik yeni bilgiler edinmelerini sağlamıştır. Hedef dil olan Türkçeye yönelik olarak yeni kültürel becerilerin kazanıldığı ve bunun hedef dilde kullanımının arttığı belirlenmiştir.

Araştırmacı günlükleri ile elde edilen verilerden kültür aktarımına ait bulgular da görüşmelerde elde edilen verileri desteklemektedir. Bu hususta araştırmacı günlüklerinde geçen ifadelerin bir kısmı şu şekildedir:

\begin{abstract}
"Kültür Günleri sürecinde mentorluk sınırlı bir grubun karşılıklı olarak kültür aktarımlarını sağlarken bir yandan da öğrencilerin karşılıklı olarak kültürel hoşgörüsünü de geliştirdi. Yabancı öğrenciler Türk kültürüne yönelik tutumlarını pozitif yönde gelişmesine ek olarak kendi kültürlerine yönelik pozitif tutumları daha da pozitif hâle gelmiş oldu. Öğgrenciler kendi kültürlerini, ülkelerini Türkiye'de tanıtmaktan dolayı duydukları memnuniyeti aradan aylar geçmiş olmasına rağmen hâlâ bizleri ziyaret edip dile getiriyorlar. Ayrıca şunu belirtmeliyim. Dünya çok farklı renklerin harmonisi ile bir arada. Öğrencilerin birlikteliği ile ortaya çıkan gökkuşağında bunu görüyorum. Bu süreç sayesinde biz de, katılan ve organize eden herkes, farkllıklara saygı göstermenin ve hoşgörünün bir değer olarak ne kadar mühim olduğunu anladık.” (2018 Eylül 25 Salı, Araştırmacı Günlüğü)
\end{abstract}

Araştırmacı günlüğünde sunulan veriler öğrencilerle yapılan görüşmenin yarı yapılandırılmış olarak gerçekleşmesi sebebiyle gözden kaçabilecek bir veriyi sunması bakımından mühimdir. Kültür Günleri’nin değerler eğitimi hususunda da katkı sağladığı, yabancı dil olarak Türkçe öğrenen öğrenciler ile mentorların karşılıklı olarak farklı kültürlere saygı göstermenin ehemmiyetini fark ettiği ve hoşgörüyü bir değer olarak kazandı̆̆ı görülmektedir.

\title{
4.2.1.6. Kültür Günleri’nin faydaları
}

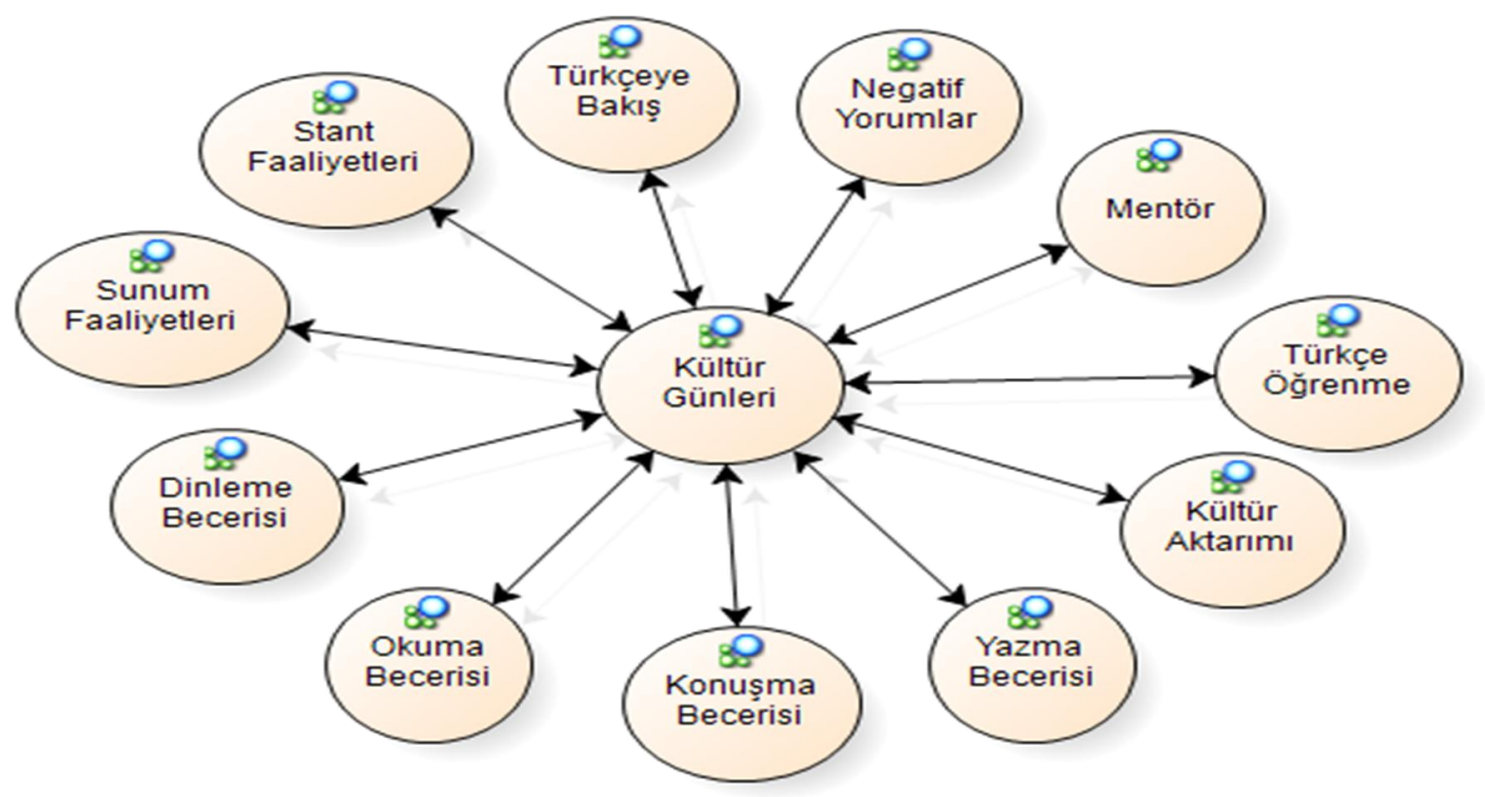

8. Şekil: Kültür Günleri’nin faydalı yönlerine yönelik kültür günleri alt modeli 
Yabancı dil olarak Türkçe öğrenen katılımcılardan elde edilen veriler katılımcıların Türkçe öğrenme süresini kısalttığı ve öğrenme hızını artırdığını göstermektedir. Dil becerilerinin ve kültürel becerilerin gelişimini hızlandırmıştır. Sunum faaliyetleri sunum becerilerini geliştirmiş ve dil becerilerinin gelişimine katkı sağlamıştır. Türkçeye yönelik olarak öğrencilerin taşıdığı pozitif tutum ise daha iyi hâle gelmiştir.

Kültür Günleri’nin negatif yönü olarak "Zaten iki gün içinde çok şey öğrenemeyiz.” tespitinin katılımcılar tarafından yapıldığı görülmektedir. Üretimin paylaşıldı̆̆ı 2 gün öğrenme için kısa olmakla beraber katılımcılar mentorluk süreci ve kuluçka dönemi etkinlikleri ile birlikte değerlendirmeleri istendiğinde sürecin Türkçe öğrenmek için yeterince uzun olduğunu ve çok sayıda başlıkta katkı sağladığını belirtmişlerdir. Bu hususu şu ifadede de görmek mümkündür:

\begin{abstract}
"Evet, katkı sağladı hocam. Konuşma, dinleme, yazma her şeye katkı sağladı; çünkü ben Merve'den her zaman konuşuyoruz WhatsApp'ta konuşuyoruz ve Facebook'ta her zaman konuşuyoruz. Yeni programlar öğretti. Çok yardım etti ve çok teşekkür ediyorum. Valla çok şeyler yaptı benim için. Hâlâ konuşuyoruz WhatsApp'tan yeni kelimeler öğretti. Eskiden bilmiyordum. Çok kelimeler Merve sayesinde öğrendim o yüzden Merve'ye çok teşekkür ediyorum. Çok katkı sağladı hocam.” (Yabancı Öğrencilerle Görüşme Kayıtları, 2. Kültür Günleri)
\end{abstract}

İfadelerde ve alt kategorilerde görüldüğü gibi mentor sisteminin öğrencilerin dil becerileri ve Türkçeye yönelik tutumu hususunda pozitif etki ettiği görülmektedir. Bunun yanında mentorlarla kurulan arkadaşlık bağ kurulmasında da katkı sağlamaktadır.

\title{
4.2.1.7. Mentorluk sistemine yönelik kültür günleri alt modeli
}

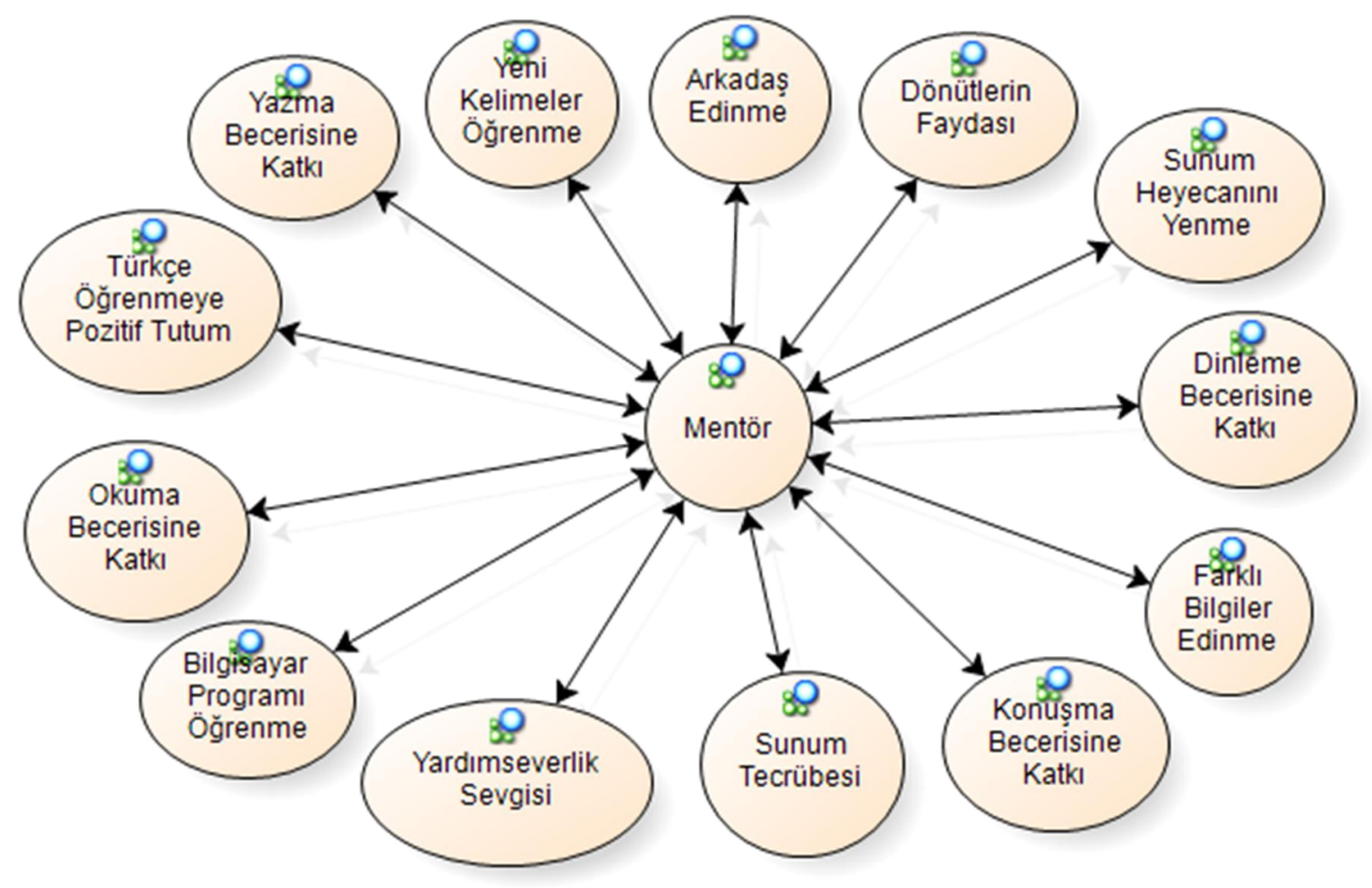

9. Şekil: Mentorluk sisteminin faydalarına yönelik kültür günleri alt modeli 
Mentorluk sisteminin yabancı dil olarak Türkçe öğrenen öğrencilere yönelik negatif bir yönü tespit edilmemiştir. Katılımcılar arkadaş edinme bakımından mentorluk sürecinin fayda sağladığını ve hem arkadaşı hem de Türkçe öğrenmede rehberi olarak kabul ettikleri mentorlarından aldıkları dönütlerin dil becerilerini geliştirmede ciddi manada etkili olduğu görülmektedir. Dinleme, okuma, konuşma ve yazma becerileri mentorların desteği, bilgi aktarımı, kültür aktarımı ve dönütleri ile gelişmiştir. Mentorların rehberliğinde Kültür Günleri'nin iki ana unsuru olan sunum ve stant faaliyetlerine hazırlanmaları hem sunum becerilerini ve hazırlıklı konuşma becerilerini hem de stantlar ile hazırlıksız konuşma becerilerini geliştirmiştir. Mentorlar ile katılımcıların pozitif bir süreç geçirmeleri de Türkçe öğrenmeye yönelik tutumlarını daha da pozitif hâle getirmiştir. Bu süreç sayesinde günlük hayattan ve akademik Türkçeden çok sayıda kelimenin öğrenilmesinin sağlandığı da görülmektedir. Bilhassa ders, sunum ve benzeri ihtiyaca dayalı bilgiler yanında Türk kültürüne dayalı özel ifadelerin (atasözü ve deyim gibi) ana dili konuşucuları bakımından daha sık kullanılması ve Türk kültürüne has beden dilinin öğretimi kültürel becerilerin de gelişmesini sağlamıştır. Değerler eğitimi bakımından yardımseverlik gelişmiştir. Son olarak mentorların eşleştĭgi öğrenciler için oluşturduğu eğitimler sayesinde Emaze, Prezi gibi Web 2.0 araçlarının sunumlarda kullanılmak üzere öğretildiği, ayrıca Photoshop gibi bilgisayar programlarının da katılımcılara öğretilmesi ile bilgisayar programları üzerine de katılımcıların eğitim aldığı belirlenmiştir.

Bu başlıkların ve sürecin değerlendirilmesinde araştırmacı günlükleri ve gözlem kayıtlarının da paralel veriler sunduğu görülmektedir. Araştırmacı günlüklerinde bu hususta ifadelerden biri de şöyledir:

\begin{abstract}
"Mentorluk sistemini Kültür Günleri’ne eklemek bu sene yaptığımız en iyi iş oldu diyebilirim. Seçilen Türkçe öğretmeni adaylarının Yabancılara Türkçe Öğretimi dersini almış olma şartının olması ve öğrencilerin alanına aşina olması da burada ciddi manada katkı sağladı. 1. sınıf öğrencileri genellikle üniversiteye uyum sağlayana kadar uzun zaman kaybetmiş oluyorlar. Öğrencilerle mentorlar arasında kurulan arkadaşlık bağı, topluca yapılan haftalık etkinlikler, tasvir çalışmaları ve benzeri, ciddi bir kaynaşma sağladı ve ö ğrenciler mentorları ile düzenli olarak çalışmak sayesinde ciddi bir gelişme gösterdi. Dün tamamladığımız Kültür Günleri hepimiz için harika bir tecrübe oldu. Ben de süreç yönetme, insan ilişkileri, alan bilgim hususunda çok sayıda kıymetli beceri kazanmış oldum.” (2018 Mayıs 10 Perşembe, Araştırmacı Günlüğü)
\end{abstract}

Araştırmacı günlüğünden elde edilen paralel verilerin yanında araştırmanın araştırmacıların kendisi için de faydalı olduğu görülmektedir. Mentorluk sisteminin haftalık etkinliklerle zenginleştirilmesi modelin etkililiğini artıran bir unsur olmuştur. 


\subsubsection{Stant faaliyetlerinin faydaları}

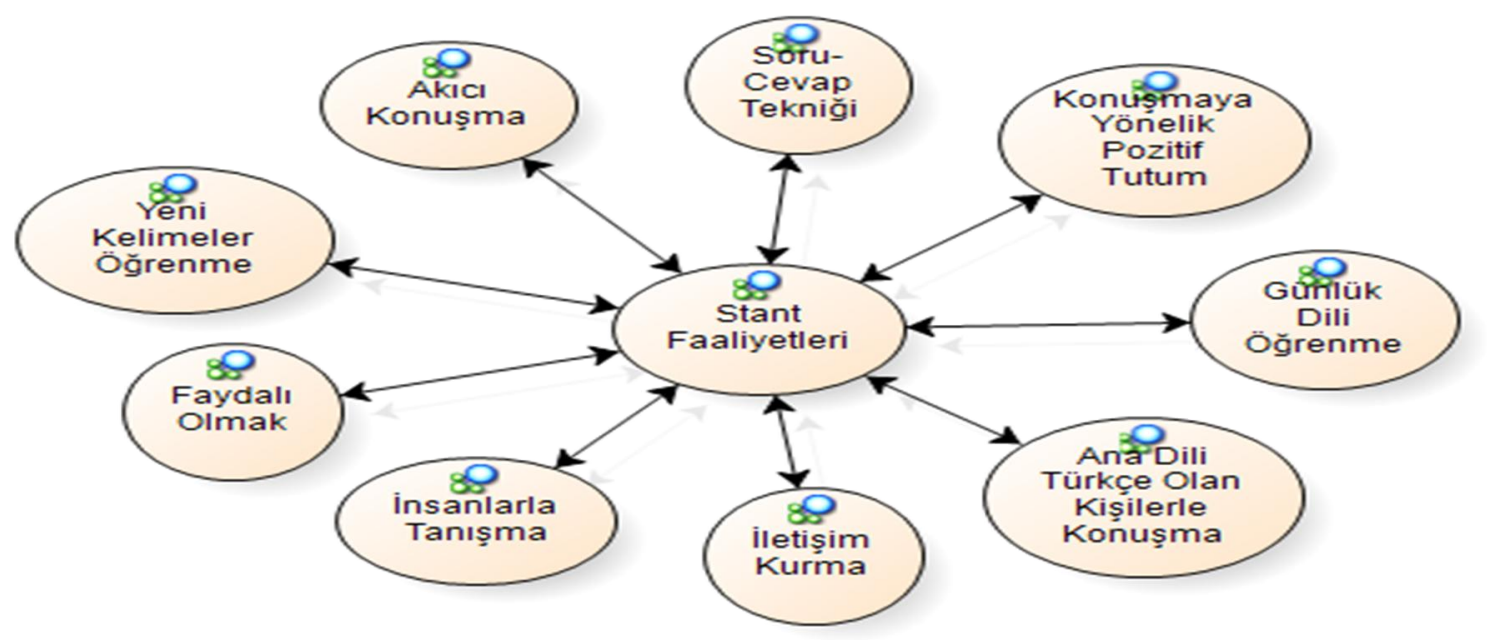

10. Şekil: Stant faaliyetlerinin faydalarına yönelik kültür günleri alt modeli

Stant faaliyetlerinin öğrencilerin akıcı konuşmasına katkı sağladığı görülmektedir. Ayrıca kendilerine gelen soruları düzenli olarak cevaplamaları da akıcı konuşma, günlük dili öğrenme ana dili Türkçe olan kişilerle konuşma, iletişim kurma ve yeni kelimeler öğrenme bakımından faydalıdır. Stant faaliyetleri faydalı olarak görülmektedir ve katılımcıların yeni insanlarla tanışarak sosyal çevrelerini geliştirmelerini sağlamıştır.

\subsubsection{Sunum faaliyetleri}

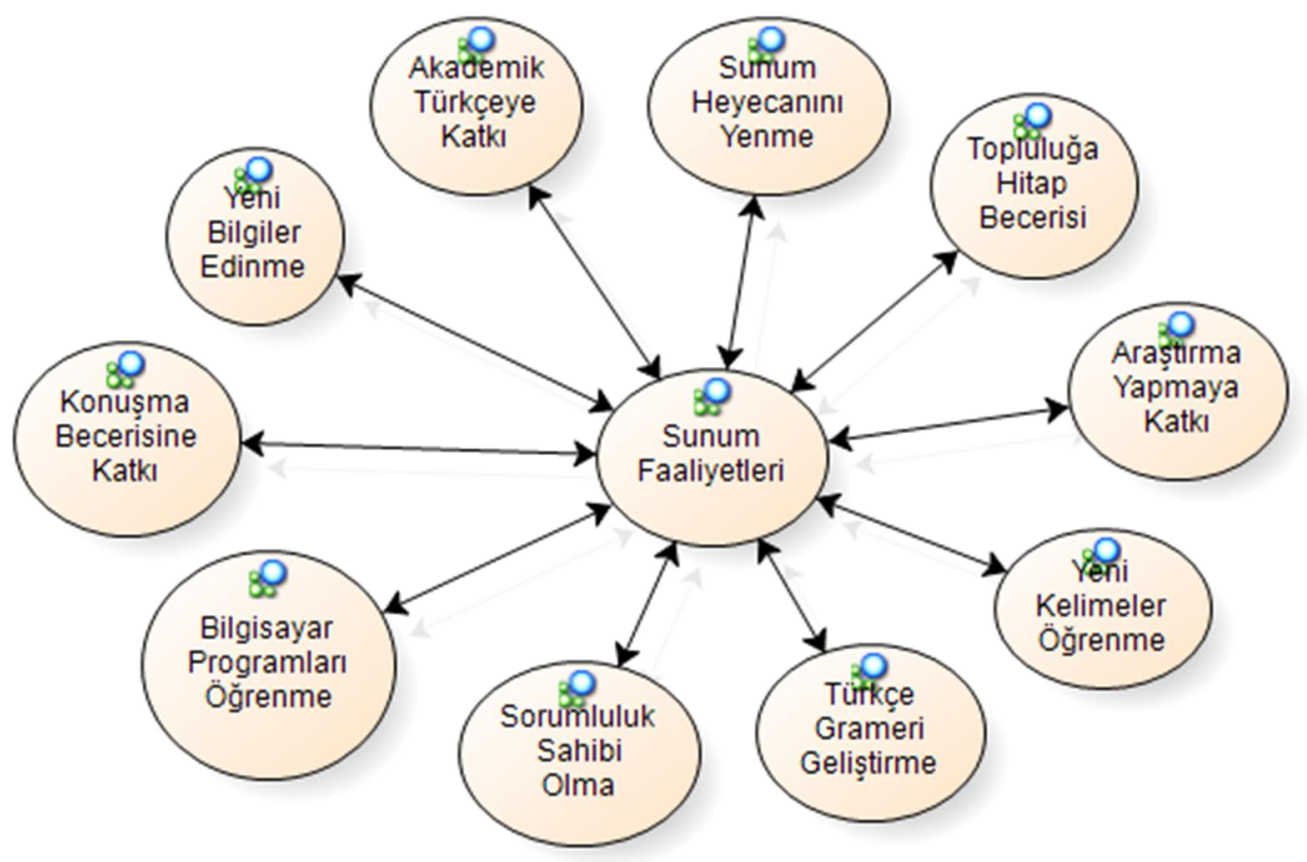

11. Şekil: Sunum faaliyetlerinin faydalarına yönelik kültür günleri alt modeli 
Katılımcıların sunuma hazırlık boyunca toplamış olduğu bilgiler ve yaptıkları pratikler ile sunumları sırasında yapmış olduğu uygulama ve paylaşma akademik Türkçe becerilerine katkı sağlamaktadır. Sunuma hazırlığa kadar olan heyecan ise sunum sırasında yenilmiştir. Hazırlık, yani kuluçka süreci boyunda yapılan araştırmalar araştırma yapma becerilerini geliştirmiştir. Bunun yanında kuluçka süreci ile birlikte düşünüldüğünde yeni kelimeler öğrenilmiş, Türkçenin gramerinin daha etkili kullanımı sağlanmış, sorumluluk duygusu gelişmiş, yeni bilgilerin edinilmesinin yanı sıra konuşma becerileri de gelişmiştir. Ayrıca sunum sırasında kullanacakları bilgisayar programlarının kuluçka süresinde öğrenilmesi bilgisayar programları kullanma becerilerinin gelişmesini sağlamıştır. $\mathrm{Bu}$ verilere paralel şekilde oluşturulan gözlem kayıtlarında şu ifadeye yer verilmiştir:

"Sunumların 1. günündeyiz. Öğrencilerin hazırlıkta duydukları heyecanı özgüven almış hâlde. Mentorlarını da izleyiciler arasında görmeleri onlara emniyet duygusu veriyor. Bilhassa bazı sunumların özenle ve kaynaklara dayanılarak hazırlanmış olduğu belli. Öğrencilerde sunumların pozitif bir gelişme sağladığını söylemek de bu bakımdan mümkün.” (2018 Mayıs 8 Salı, Gözlem Kayıtları)

\subsubsection{Türkçe öğrenmeye yönelik katkılar}

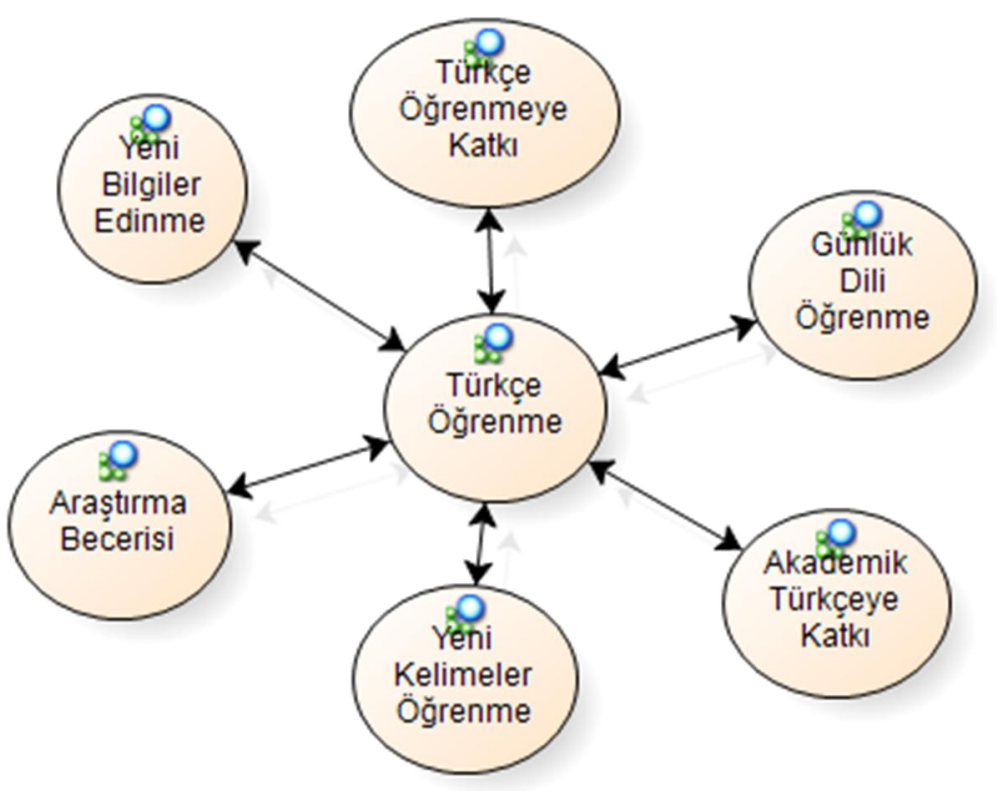

12. Şekil: Türkçe öğrenmeye yönelik katkılar için kültür günleri alt modeli

Öğrencilerin Türkçeyi öğrenme süreçlerinde yaptıkları araştırmaların etkili olduğu görülmektedir. Mentorların rehberliği doğrultusunda gerçekleşen bu araştırmalar yeni bilgiler edinmeyi, Türkçe öğrenme sürecinin hızlanmasını sağlanmıştır. Ayrıca kuluçka dönemi ve Kültür Günleri içinde yapılan faaliyetler sayesinde günlük dili öğrenme, akademik Türkçenin gelişmesi ve yeni kelimelerin öğrenilmesi mümkün olmuştur. 


\title{
4.2.1.11. Türkçeye yönelik tutum
}

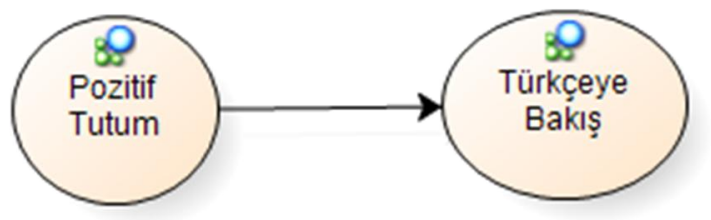

13. Şekil: Yabancı dil olarak Türkçe öğrenmeye yönelik tutuma dair kültür günleri alt modeli

$\mathrm{Bu}$ temada toplanan kategoriler öğrencilerin Türkçeye yönelik pozitif olan bakış açısının daha da pozitif hâle geldiğini göstermektedir. Bu husus araştırmacı günlüklerine şu ifadelerle belirtilmektedir:

"Dün biten Kültür Günleri sonrasında herkes çok mutlu. Bir sonraki Kültür Günleri için herkes sabırsızlandığını söylüyor. Bir yandan da Türkçe öğrenmenin çok güzel bir süreç olduğunu ve bunun için teşekkür ettiğini söyleyen çok sayıda öğrencimiz var. Bu insana manen büyük bir haz veriyor. Bu işi sevmemin en mühim sebebi dünyanın dört bir yanından hayal eden, keşfeden ve üreten zihinler. ()" (2018 Mayıs 12 Cumartesi, Araştırmacı Günlüğü)

\subsubsection{Mentorlara yönelik kültür günleri bulgular}

Bu başlık altında mentorlarla yapılan görüşmelerden elde edilen verilerin içerik analizi ile incelenmesi neticesinde oluşan bulgular gözlem ve görüşme kayıtları doğrultusunda incelenmiştir.

\subsubsection{Sunulan uygulama imkânları}

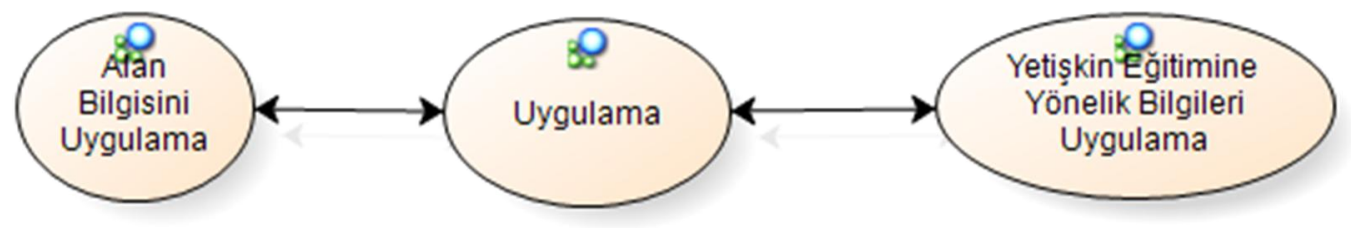

14. Şekil: Sunulan uygulama imkânlarına yönelik kültür günleri alt modeli

3. ve 4. sınıftan seçilen Türkçe öğretmeni adaylarının mentorluk sürecine kadar olan zaman diliminde almış oldukları eğitimi uygulama imkânı buldukları görülmektedir. Süreç boyunca alan eğitimleri ve yetişkin eğitimine yönelik elde ettikleri bilgi birikimini sahada uygulama imkânı bulmuşlardır. Araştırmacı günlüklerinde bu hususta şu ifadeler yer almaktadır:

\begin{abstract}
“İlk başta tamamen yabancılara Türkçe öğretimi için sunmayı amaçladığımız bu model Türkçe öğretmeni adaylarının yetişkin eğitimi ve alan bilgilerini sahada uygulamaları için de faydalı bir sürece evrildi. Seçilen mentorların öğretirken de öğrendiklerini görebiliyorum. Bir yandan onlar yabancı öğrencilere dönüt verirken biz de onlara dönütler sunuyoruz. Bu araştırmanın biz hocalar için de bir ö̆grenme süreci doğurduğunu söylemem gerek." (2018 Mart 28 Çarşamba, Araştırmacı Günlüğü)
\end{abstract}

Araştırmacı günlüğünde öğrenci görüşlerinden farklı olarak süreçte araştırmacıların da yeni bilgiler ve tecrübeler edindiği görülmektedir. Ayrıca öğretme sürecinde mentorların hocalarından aldıkları dönütler araştırma sürecinde yeni öğrenmelere de imkân sağlamıştır. 


\subsubsection{Psikolojik fayda}

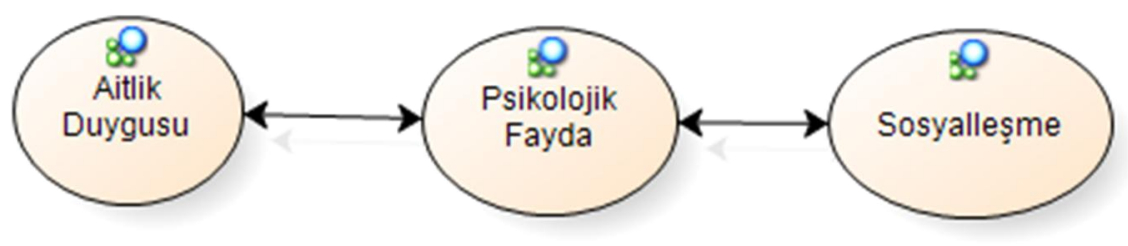

15. Şekil: Psikolojik faydalara yönelik kültür günleri alt modeli

Kültür Günleri mentorlarda bir gruba ait olma hissini sağlamaktadır. Bunun yanında mentorların yabancı dil olarak Türkçe öğrenen öğrencilerle akran olması sosyalleşmeyi de sağlamaktadır.

\subsubsection{3. Öğrenme alanı oluşturma}

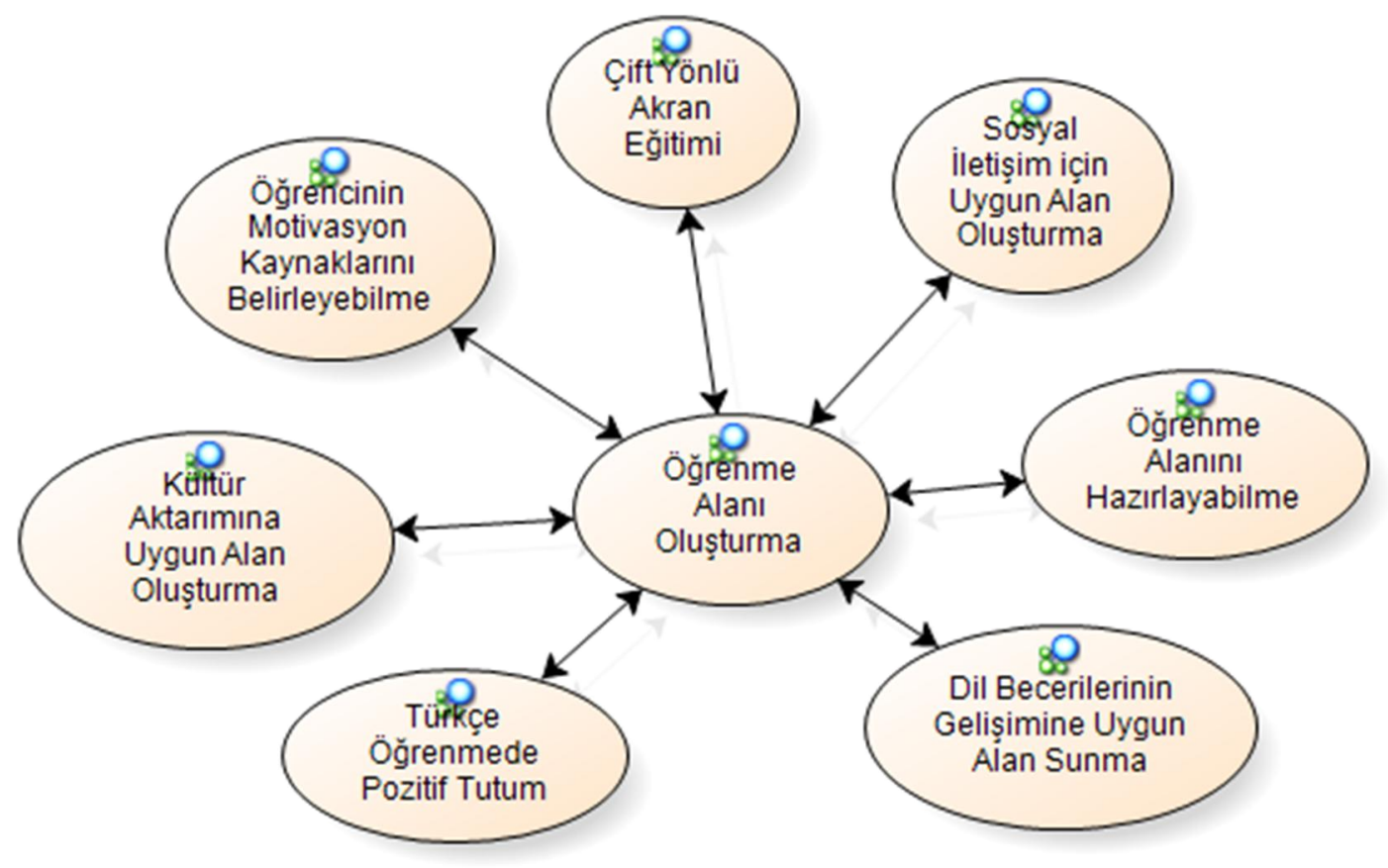

16. Şekil: Mentorların öğrenme alanı oluşturmasına yönelik kültür günleri alt modeli

Yapılan analizler mentorların hem yabancı dil olarak Türkçe öğrenen öğrenciler için hem de kendileri için öğrenme alanı oluşturduklarını göstermektedir. Mentorlar ve yabancı öğrenciler akran kabul edecek yaştadırlar. Bu sebeple çift yönlü akran eğitimi de gerçekleşmiş, yani öğretmen adayları Türkçe öğretirken yabancı öğrencilerden onların dilleri, kültürleri ve ilgi alanları hususunda bilgiler edinmişlerdir. Mentorlar öğrencilerin sunum ve stant faaliyetlerine destek verirken motivasyon kaynaklarını da göz önünde bulundurdukları görülmektedir. Bir yandan da kültür aktarımına uygun bir alan oluşturmada da başarılı olmuşlardır. Mentorların varlığının yabancı öğrencilerin Türkçe öğrenmeye yönelik tutumlarını daha da pozitif hâle getirdiği görülmektedir. Ayrıca bütün bu sürecin gerçekleşmesinde sosyal iletişim için uygun alanın oluşturulmasında mentorlar başarılı olmuştur. 


\subsubsection{Organizasyon becerileri}

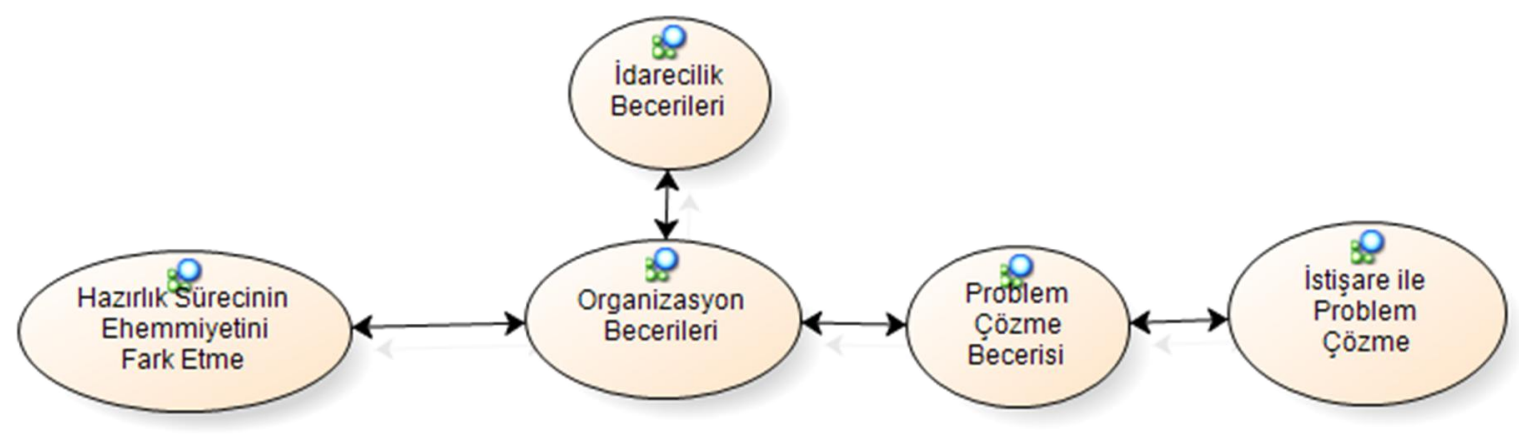

17. Şekil: Mentorların organizasyon becerilerine yönelik kültür günleri alt modeli

Kültür Günleri içinde mentor olarak vazife alan ekibin aynı zamanda organizasyonu düzenleyen ekibin de parçası olması sebebiyle organizasyon becerilerinde ciddi gelişmeler görüldüğü belirlenmiştir. Katılımcllar bir organizasyona hazırlık sürecinin ehemmiyetini fark etmiş, idarecilik becerilerini geliştirmiştir. Ayrıca problem çözme becerilerinin istişare ederek problemlerini çözme gibi yollarla ciddi manada geliştiği görülmektedir. Benzer veriler araştırmacı günlüklerinde şu şekilde geçmektedir:

“Az önce Kültür Günleri için yapacağımız alımları konuşmak üzere öğrencilerimle konuştum. Sadece derse girmede değil, büyük bir organizasyonu yönetme noktasında da tecrübe edinmeleri oldukça güzel. Bir organizasyonu yapmak bazen yorucu olsa da böyle bir etkinliğin giderlerini sadece sponsorluk gibi başlıklarla çözebilecek, aynı zamanda da yönetebilecek yol arkadaşlarına sahip olmak harika bir şey.” (2018 Mayıs 2 Çarşamba, Araştırmacı Günlüğü)

\subsubsection{Kültürel beceriler}

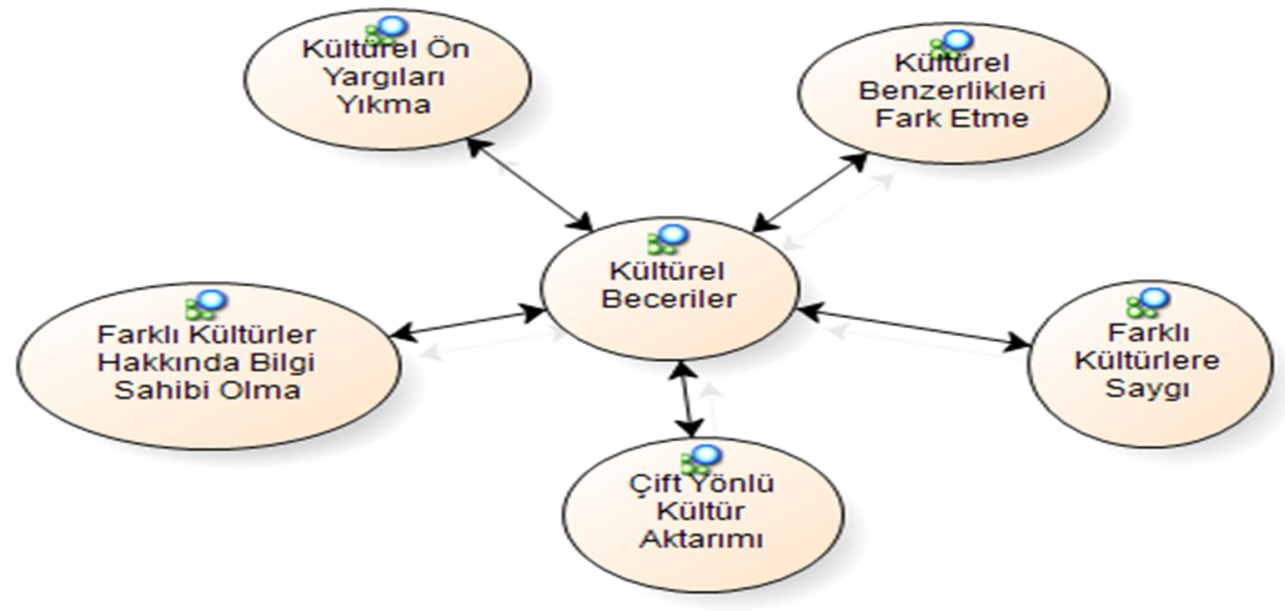

18. Şekil: Mentorların kültürel becerilerine yönelik kültür günleri alt modeli.

Türkçe öğretmeni adaylarından bazılarının kültürel ön yargılara sahip olduğu; ancak sürecin bu ön yargıları pozitif tutuma çevirdiği belirlenmiştir. Mentorlar farklı kültürler ile Türk kültürü arasındaki benzerlikleri fark etme şansına sahip olmuşlardır. Bu vaziyet aynı zamanda farklı kültürlere saygıyı da 
beraberinde getirmiştir. Süreçte mentorlar yabancı öğrencilerle çift yönlü kültür aktarımını temin etmiştir.

\subsubsection{Hayatı planlama}

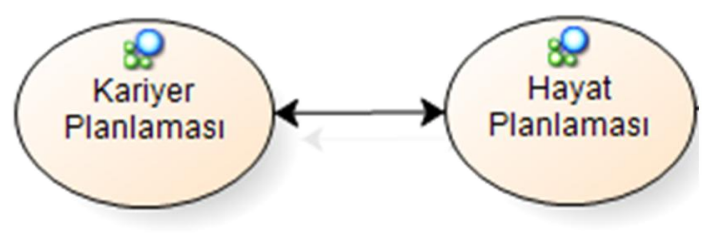

19. Şekil: Hayatı planlamaya yönelik kültür günleri alt modeli

Kültür Günleri’nin araştırmanın amaçlarından bağımsız olarak çıkan faydalarından olan mentorların hayat planlamasına olan etkisi için kariyer planlamalarına yönelik bulgular elde edilmiştir. Mentorlardan bir kısmı yabancı dil olarak Türkçe öğretiminde kariyerini sürdürmek istediğini belirtmiştir.

\subsubsection{Alan bilgisi}

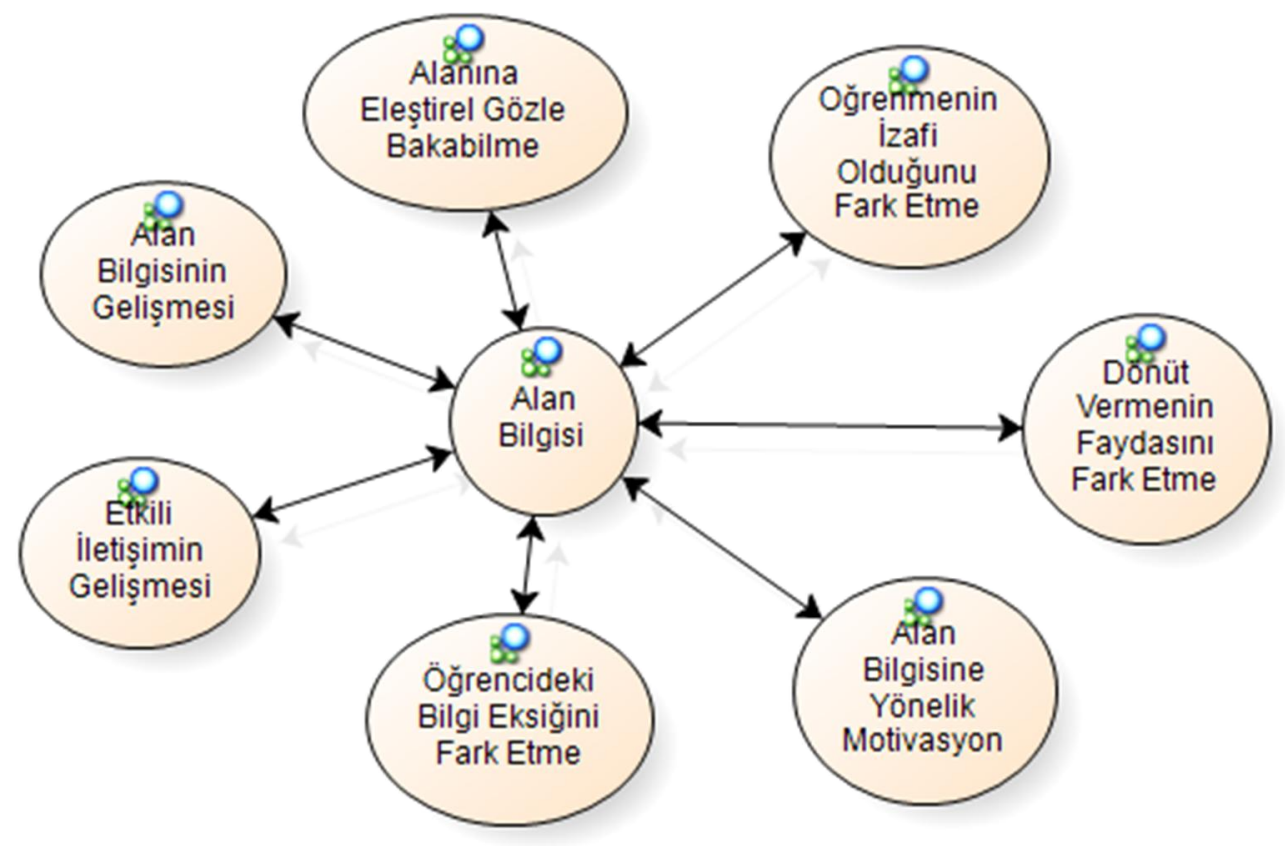

20. Şekil: Mentorların alan bilgisine etkisi bakımından kültür günleri alt modeli

Mentorların kendi alanından aldığı eğitime eleştirel bir gözle bakabilme becerisi kazandığı görülmektedir. Süreç boyunca alanlarına yönelik bilhassa uygulamaya dayalı bilgileri genişlemiştir. Etkili iletişim becerileri gelişmiş, yabancı öğrencilerdeki bilgi eksiklerini fark ederek onları öğrenme sürecini dâhil edebilmişlerdir. Sürecin kendi alanları hakkında bilgi edinmeye yönelik olarak motivasyonlarını da artırdığı görülmektedir. Yabancı öğrencilere yönelik olarak kuluçka süreci ve 
Kültür Günleri boyunca verilen dönütler, dönüt vermenin ehemmiyetini de fark etmelerini sağlamıştır. Son olarak mentorların eğitimin her öğrenci için izafi olduğunu fark ve tecrübe ettiği bir süreçten geçtiğini söylemek mümkündür.

\subsubsection{Kültür Günleri'nin geliştirilmesi için yapılabilecekler}

Mentorlar tabii bir süreçle öğrenmenin gerçekleştiğini belirtmektedir. Bu sürecin daha sistemli hâle gelmesi için mentorlara öğretmenlik yapmaları için daha fazla fırsat verilebilir. Böylece mentorların daha sistemli bir eğitim sürecinde tecrübe ve bilgi kazanmaları ve eğitim vermeleri mümkündür.

\subsection{Nitel bulguların güvenilirlik derecesi}

Miles and Huberman (1994) tarafından geliştirilmiş güvenilirlik formülü doğrultusunda değerlendirmek üzere yabancı öğrenciler ve mentorlarla yapılan görüşmelerden elde edilen bulgular 1'er alan uzmanına sunulmuştur. Yabancı dil olarak Türkçe öğrenen öğrencilerle yapılan görüşmelere ait bulgular için ilk oturumda \%70 oranı üstünde güvenilir olduğu sonucuna varılmıştır. Bu oran formül doğrultusunda yeterli olsa da uzman tarafından düzeltme verilen kategoriler için yeniden düzenleme yapılmış ve kategorilerin tamamında görüş birliğine varılmıştır.

Mentorlarla yapılan görüşmede ise uzmanla yapılan ilk oturumda yine \%70 oranı üstünde güvenilirlik elde edilmiştir. Düzeltme verilen kategoriler için ise uzmanla yapılan 2. görüşme ile kategorilerin tamamında görüş birliği sağlanmıştır.

\section{Bulguların değerlendirilmesi}

Bu başlık altında araştırma sürecinden elde edilen veriler literatür ile mukayeseli olarak tartışılmıştır. Tartışma neticesinde ortaya çıkan sonuçlar ilgili kısımda açıklanmış, gelecek araştırmalarla ilgili yapılabilecekler sıralanmıştır.

\subsection{Tartışma}

Yabancı dil olarak Türkçe öğrenen öğrencilerin ticaret yapma, eğitim ve iş imkânı, şahsi ilgi ve ihtiyaçlar ile sınıf içi iletişim kurma gibi ihtiyaçlarının olmasının (Çalışkan \& Çangal, 2013) Türkçe öğrenmeden elde ettikleri fayda ile de örtüştüğü görülmektedir. Araştırmanın amaçlarından olan dil becerilerinin geliştirilmesinde öğrencilerden ve mentorlardan elde edilen bulgular farklı öğrencilerin Türkçeyi farklı algıladıkları (Pilanci \& Saltık, 2018) gerçeğini fark ettikleri ve buna uygun olarak eğitimin her öğrenci için izafi olduğunu tecrübe ederek süreci şekillendirdiklerini ortaya koymaktadır. Bazı etkinliklerin motivasyonu düşürebilir olması (Biçer, 2016) sebebiyle mentorların eşleştikleri yabancı öğrencilere araştırmacılardan aldıkları dönütler doğrultusunda onlara uygun etkinliklerde yer almalarının fayda sağladığı görülmektedir. Yazma becerisinde (Tiryaki, 2017), stant faaliyetleri ile hazırlıksız konuşma becerisinde (Tunçel, 2015), dinleme ve okuma becerilerinde (Altunkaya, 2017), yaşadıkları kaygıların ve dil becerilerini geliştirme ihtiyaçlarının giderilmesinde modelin faydalı olduğu görülmektedir. Ayrıca aktif öğrenme tabanlı etkinliklerle dinleme (Memiş, 2019) ile konuşma ve yazma (Şen \& İşigüzel, 2018) becerilerinde elde edilen pozitif sonuçlarda olduğu gibi Kültür Günleri modelinde de pozitif sonuçlandığı görülmüştür.

Çalışma Kültür Günleri’nin eğitim-öğretim sürecindeki motivasyon kaynaklarının belirlenmesi (Dekker \& Fischer, 2008), dilde akıcılık (Oberg \& Ramïrez, 2006) gibi hususlarda kültürün etkileyici 
rolüne dair literatürdeki çalışmalarla da örtüşmektedir. Kültürün ana faktörlerinden ferdiliğe karşı kolektif hareket etme (Hofstede \& Bond, 1984) prensibinin araştırmanın ana başlıklarından birini oluşturduğu model mentorlarda da aitlik hissi uyandırmış ve topluluk hâlinde hareket etmenin aktif katılımı artırdığı görülmüştür. Ayrıca 5. dil becerisi olan kültürün (Kramsch, 1991) ve onun üzerine bina edilen Kültür Günleri'nin burada da dinleme, konuşma, okuma ve yazma becerilerine katkı sağladığı görülmektedir. Bu sonuç literatürde kültür temelli etkinliklerin etkili bir öğrenme sağladığı sonucu ile de örtüşmektedir (Scheu, 1996).

Literatürdeki çalışmalarda olduğu gibi (Moralı \& Göçer, 2019) 2016-2017 yllında kültür aktarımına yönelik ilgili hedef kitlelerle yapılan görüşmelerde de benzer sonuçlar elde edilmiştir. Süreçte yabancı öğrencilerin ve Türk öğrencilerin millî folkloru yansitan kıyafetler giymeleri hedef dilin kültürü hakkında ayrıntılı bilgi öğrenme isteğini (Alyılmaz \& Onur, 2018) karşılamış görünmektedir. Farklı kültürlerden gelen öğrencilerin uyum sürecinde daha fazla problem yaşamasının da (Güleç \& Bekir, 2013) bu etkinlikte her kültürün ayrı bir değer ve tanınması gereken kıymetli bir unsur olarak sunulması sayesinde önüne geçildiği görülmüştür. Kültür Günleri bu yönü ile farklı kültürleri dezavantaj olmaktan çıkararak Türkçe öğrenmede motivasyon ve bilgi kaynağına dönüştürmüştür.

Süreç boyunca öğrencilerin mentorlar ve yapılan etkinlikler yoluyla Türk kültürü hakkında bilgilerini artırması söz konusudur. Bilhassa mentorlar yoluyla yapılan faaliyetlerin yabancı öğrencilerin müdahil oldukları kültür çevresinde elde ettikleri tecrübelerle formal ve informal öğrenmelerin (Kozulin, 2003) gerçekleştiği görülmektedir. Motivasyon ve akademik başarıda sosyokültürel faktörlerin hesaba katılmasının (Yuanfang, 2009) yabancı dil olarak İngilizce öğretimi (Behroozizad et al., 2014) alanında elde edilen bulgularla benzer pozitif sonuçlar sunduğu görülmektedir.

Dilde sosyalleşmenin (Garrett, 2008) süreç boyunca mentorlarla yabancı öğrenciler arasındaki ilişkilerde faydalı bir unsur olarak öne çıktığı görülmüştür. Bu sayede öğrenme sürecinin hızlandığı da söylenebilecektir. Süreç boyunca gerçekleşen sosyalleşmenin pozitif ilişkiler doğurduğu görülmektedir.

Farklı alanlarda yapılan araştırmalar alanı ile ilgili ileri metot ve tekniklerin öğrenilmesi ve uzmanlaşma isteğinin yüksek lisans alan tercihinde etkili olduğunu göstermektedir (Alabaş, Kamer, \& Polat, 2012). Ek olarak lisansüstü eğitimin faydalı bir süreç olarak görülmesi söz konusudur (Er \& Ünal, 2017). Ayrıca öğrenim gördükleri program ve yerleşme sıralarının etkili olabileceği (Tezcan \& Genç, 2015) belirtilmiştir. Kültür Günleri’nde ise Türkçe eğitimi alanının spesifik bir alt başlığı olan yabancılara Türkçe öğretimi sahasında uzmanlaşmaya yönelik motivasyon oluşmuş ve kariyer planlamalarını Kültür Günleri etkilemiştir.

Yapılan çalışmalarda öğretmen adaylarının alan bilgisine yönelik dersleri gerçek hayattan uzak ve gereksiz bulduklarına işaret edilmektedir (Beşoluk \& Horzum, 2011). Elde edilen bulgular Kültür Günleri’nin uygulamaya dayalı yapısı ile öğretmen adaylarına hem teorik bilgileri uygulama imkânı vermiş hem de uygulama ile teori arasındaki farkı görmelerini sağlayarak alan bilgilerine eleştirel gözle bakmalarını sağlamıştır. Bu sebeple hem teorik bilgiler hem de uygulamaya dönük bilgiler ve tecrübe edinimi bakımından öğretmen adaylarına faydalı bir modelin literatüre kazandırıldığı söylenebilecektir.

\subsection{Sonuçlar}


Sosyokültürel teori üzerine bina edilen Kültür Günleri modelinin araştırma amaçlarını gerçekleştirdiği görülmektedir. Yabancı dil olarak Türkçe öğrenen katılımcıların dinleme, okuma, konuşma ve yazma becerileri ile kültürel becerileri pozitif yönde gelişmiştir. Yabancı dil olarak Türkçe öğrenmeye yönelik tutum daha iyi seviyededir. Dil becerilerini kullanmaya yönelik kaygıların azaldığını ve süreç sonunda özyeterlilik algılarının yükseldiği belirlenmiştir.

Türkçe öğretmeni adaylarından oluşan mentorlarda ise alan bilgisinin geliştiğini söylemek mümkündür. Model alan bilgisi, organizasyon becerileri, kültürel beceriler ve kariyer planlama alanında da faydalı olabilmektedir.

\subsection{Gelecek araştırmalar}

Kültür Günleri’nin parametrik veri setleri ile çalışılması yabancı dil olarak Türkçe öğrenen öğrencilerin tamamını temsil eden bulgular ortaya koyabilmesini bakımından mühimdir. Bu sebeple gelecek araştırmalarda akademik başarı değişkenlerinin de dâhil edilmesi ve modelin daha geniş kitlelere uygulanması mümkündür. Ayrıca model çok sayıda değişkeni aynı yönde pozitif olarak etkilemiş, yabancı dil olarak Türkçe öğrenenler gibi Türkçe öğretmeni adaylarının da farklı değişkenlerde pozitif gelişme göstermesini sağlamıştır. Bu sebeple Türkçe öğretmeni adayları ile ilgili daha derinlikli veri elde edildiği ve mentorluk sürecinin daha detaylı incelendiği çalışmaların yapılması gerekmektedir.

Mentorlarla kurulan arkadaşlık bağı da mentolarla oluşturulmuş sosyometrik olarak pozitif bir grubun Türkçe öğrenme de katkı sağlayabileceğini göstermektedir. Bu başlık için de parametrik test grupları ile yeni araştırmalarda kurulacak hipotezlerin test edilmesi katkı sağlayabilecektir. Öğrenciler ve mentorlardan elde edilen öğrenmeye yönelik pozitif bulgular proksimal öğrenme alanlarının (Lantolf, 2000) ne derecede gerçekleştiğine yönelik yapılacak yeni çalışmalara da dayanak oluşturmaktadır. Ayrıca araştırma bulguları sosyokültürel teori üzerine temellenen yeni öğrenme modellerinin yetişkin eğitiminde kullanılmasına (Smith \& Pourchot, 2013) yönelik yabancı dil olarak Türkçe öğretiminde potansiyel oluşturmaktadır.

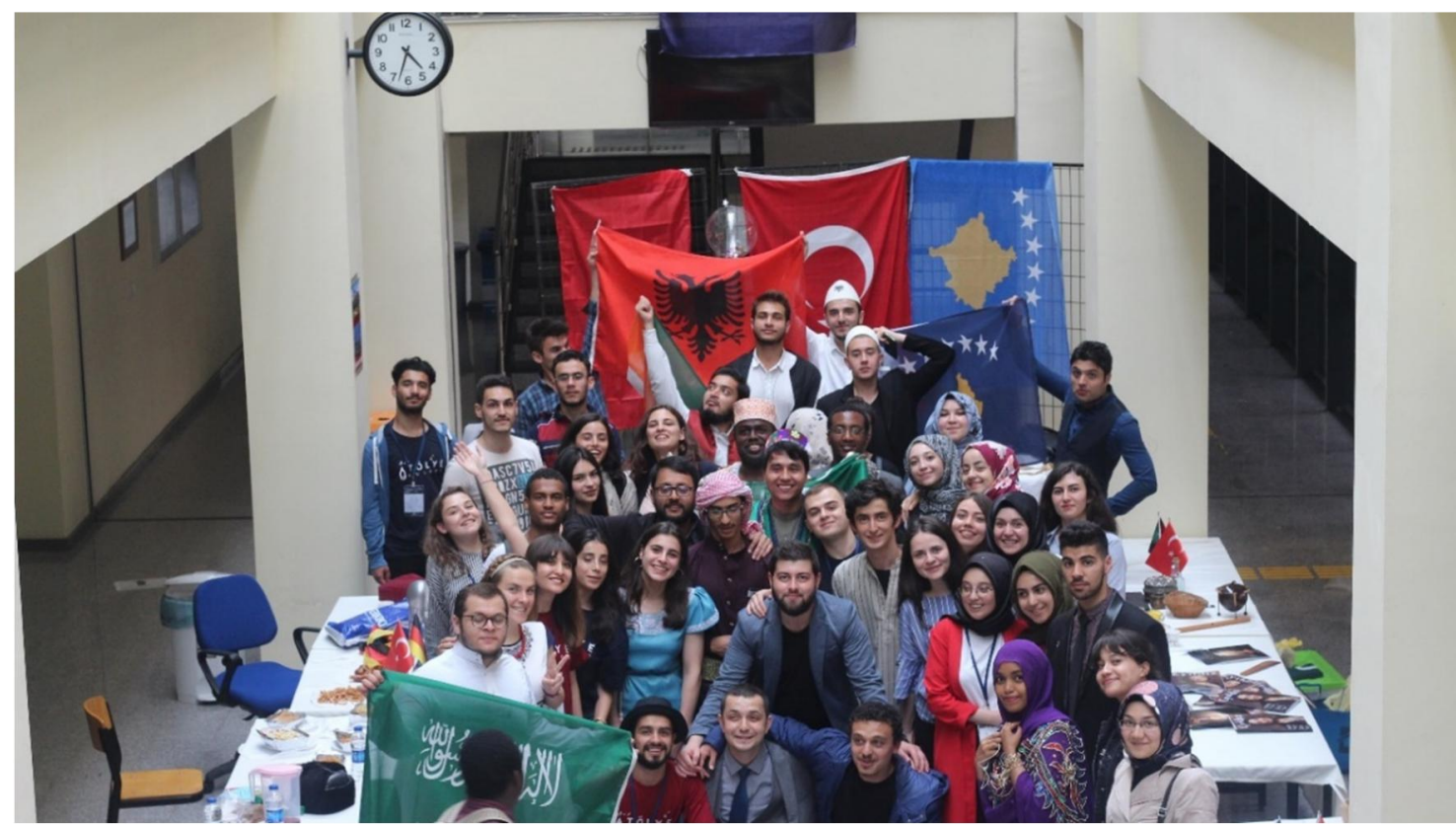

2. Fotoğraf: 2. Kültür Günleri Finali, 2018 Mayıs 9 Çarşamba 


\section{Teşekkürler}

Mentorluk sürecini organize edilmesi ve Kültür Günleri'nin gerçekleştirilmesi hususunda araştırmacıların da kurucularından olduğu Dil Atölyesi’ne ve Kültür Günleri sürecinde mentor veya organizatör olarak çalışmış olan Dil Atölyesi üyesi ve 2017-2018 eğitim-öğretim yılı başkan yardımcısı Nazife Ece Kılınç'a, saymanı Elif Kılıç’a, eğitim departmanı başkanı Ayşenur Keskin'e, sekteri Nurcihan Kabacı'ya, sosyal sorumluluk departmanı başkanı Nur İpek Toprak'a, basın-yayın departmanı başkanı Selçuk Emre Ergüt'e, sponsorluk departmanı başkanı Beril Akdeniz'e, sosyal sorumluluk departmanı başkanı Esra Bozkurt’a, sosyal sorumluluk departmanı başkanı Kübra Aktaş'a, denetim kurulu başkanı Bünyamin Şahin'e, grafik-tasarım-teknoloji departmanı başkanı Aykut Korkmaz'a, kulüp üyeleri Abdülmuttalip Dursun'a, Songül Karadağ'a, Merve Çar’a, Goncagül Özdemir'e, Tahsin Yılmaz'a, Yunus Avcı'ya, Emine Demirtaş'a, Zeynep Kartav'a, Ümmühani Yanar'a, Elif Şahin'e, Yusuf Babahanov'a, Meryem Gür'e, Sıddıka Büşra Özsoy'a, Aynur Keskin'e ve Betül Horozoğlu'na teşekkür ederiz.

Son olarak makale sürecinde görüş ve değerlendirmesi ile sürece destek sağlayan Doç. Dr. Bayram Baş’a ve Arş. Gör. Dr. Kübra Özçetin’e teşekkür ederiz.

\section{Kaynaklar}

Açıkgöz, K. Ü. (2003). Aktif öğrenme: Eğtim Dünyası Yayınları.

Alabaş, R., Kamer, S. T., \& Polat, Ü. (2012). Öğretmenlerin Kariyer Gelişimlerinde Lisansüstü Eğitim: Tercih Sebepleri ve Süreçte Karşılaştıkları Sorunlar/Master's Degree Education in The Career Development of Teachers: Reasons of Preference and The Problems That They Face throughout The Process. E-Uluslararası Eğitim Araştırmaları Dergisi, 3(4), 89-107.

Altunkaya, H. (2017). Yabancı Dil Olarak Türkçe Öğrenenlerin Dinleme ve Okuma Kaygıları. Education Sciences, 12(3), 107-121.

Alyılmaz, C., \& Onur, E. (2018). İkinci Dil Olarak Türkçe Öğrenen Öğrencilerin Türk Kültürüne Yönelik Farkındalıklarının İncelenmesi. Abant İzzet Baysal Üniversitesi Eğitim Fakültesi Dergisi, 18(3), 1269-1285.

Barın, E. (2004). Yabancılara Türkçe öğretiminde ilkeler. Hacettepe Üniversitesi Türkiyat Araştırmaları (HÜTAD)(1), 19-30.

Behroozizad, S., Nambiar, R., \& Amir, Z. (2014). Sociocultural theory as an approach to aid EFL learners. Reading, 14(2).

Beşoluk, Ş., \& Horzum, M. B. (2011). Öğretmen adaylarının meslek bilgisi, alan bilgisi dersleri ve öğretmen olma isteğine ilişkin görüşleri. Ankara Üniversitesi Ĕğitim Bilimleri Fakültesi Dergisi, 44(1), 17-50.

Biçer, N. (2016). Yabancılara Türkçe Öğretiminde Motivasyona İlişkin Öğrenci Görüşleri ve Sınıf içi Gözlemler/Views of Students about their Motivation in Teaching Turkish as a Foreign Language and Classroom Observations. Ana Dili Eğitimi Dergisi, 4(1), 84-99.

Byrnes, H. (2009). Advanced language learning: The contribution of Halliday and Vygotsky: A\&C Black.

Corbin, J. M., \& Strauss, A. (1990). Grounded theory research: Procedures, canons, and evaluative criteria. Qualitative sociology, 13(1), 3-21.

Creswell, J. W. (2012). Educational research: planning, conducting and evaluating quantitative and qualitative research ( $4^{\text {th }}$ ed.). 501 Boylston Street, Boston,: Pearson Education, Inc.

Çalışkan, N., \& Çangal, Ö. (2013). Yabancılara Türkçe öğretiminde dil ihtiyaç analizi: Bosna-Hersek örneği. Abant İzzet Baysal Üniversitesi Ĕ̆itim Fakültesi Dergisi, 4(2), 101-136. 
Dekker, S., \& Fischer, R. (2008). Cultural differences in academic motivation goals: A meta-analysis across 13 societies. The Journal of Educational Research, 102(2), 99-110.

Er, H., \& Ünal, F. (2017). Sosyal Bilgiler Öğretmen Adaylarının Lisansüstü Öğretime İlişkin Görüsslerinin Değerlendirilmesi. Journal of Kirsehir Education Faculty, 18(2).

Fahim, M., \& Haghani, M. (2012). Sociocultural Perspectives on Foreign Language Learning. Journal of Language Teaching \& Research, 3(4), 693-699.

Garrett, P. B. (2008). Researching language socialization. Encyclopedia of language and education, 10, 189-201.

Güleç, İ., \& Bekir, İ. (2013). Türkçe Öğrenen Yabancıların Günlük Yaşama İlişkin Kültürel Algıları Üzerine Bir Araştırma. Sakarya University Journal of Education, 3(3), 95-106.

Hofstede, G., \& Bond, M. H. (1984). Hofstede's culture dimensions: An independent validation using Rokeach's value survey. Journal of cross-cultural psychology, 15(4), 417-433.

Jacks, T., Wallace, S., \& Nemati, H. (2012). Impact of culture on knowledge management: A metaanalysis and framework. Journal of Global Information Technology Management, 15(4), 8-42.

Karatay, H., \& Kartallığlu, N. (2016). Yabancı Dil Olarak Türkçe Öğrenme Tutumu ile Dil Becerileri Edimi Arasındaki İlişki. Abant İzzet Baysal Üniversitesi Sosyal Bilimler Enstitüsü Dergisi, 16, 203-214.

Kozulin, A. (2003). Psychological tools and mediated learning. Vygotsky's educational theory in cultural context, 15-38.

Kramsch, C. (1991). Culture in language learning: A view from the United States. Foreign language research in cross-cultural perspective, 217-240.

Lantolf, J. P. (2000). Sociocultural theory and second language learning (Vol. 78): Oxford University Press.

Memiş, M. R. (2019). Türkçe Öğrenenlerin Dinleme Başarısını Artırmak İçin Kullanılabilecek İki Farklı Uygulama. Ondokuz Mayıs Üniversitesi Eğitim Fakültesi Dergisi, 38(2), 107-120.

Miles, M. B., \& Huberman, A. M. (1994). Qualitative data analysis: An expanded sourcebook: sage.

Moralı, G., \& Göçer, A. (2019). Yabancı Dil Olarak Türkçe Öğretiminde Kültür Paylaşımına Yönelik Öğretmen Görüşleri. Ana Dili Eğitimi Dergisi, 7(4), 1115-1129.

Oberg, G., \& Ramirez, M. (2006). Cross-linguistic meta-analysis of phonological fluency: Normal performance across cultures. International Journal of Psychology, 41(5), 342-347.

Pilanci, H., \& Saltık, O. (2018). Yabancılara Türkçe Öğretiminde Dil Bilgisi İçeriğini Etkileyen Faktörler: A1, A2 Düzeyleri. Uluslararası Beşeri Bilimler ve Eğitim Dergisi, 4(9), 122-149.

Scheu, D. (1996). Integrating Cultural Activities in the Foreing language Classroom. Cuadernos de Filologia Inglesa, 5(1).

Schreier, M. (2014). Qualitative content analysis in practice (K. Metzler Ed. $3^{\text {rd }}$ ed.). Thousand Oaks, California: Sage publications.

Silverman, D. (2013). Doing qualitative research: A practical handbook: SAGE publications limited.

Smith, M. C., \& Pourchot, T. (2013). Adult learning and development: Perspectives from educational psychology: Routledge.

Steel, P., \& Taras, V. (2010). Culture as a consequence: A multi-level multivariate meta-analysis of the effects of individual and country characteristics on work-related cultural values. Journal of International Management, 16(3), 211-233.

Şahin, Ç., Kurudayığlu, M., Tunçel, H., \& Öztürk, Y. A. (2013). Türkçe öğretmeni adaylarının lisans düzeyinde verilen yabancılara Türkçe öğretimi (YTÖ) dersine yönelik özyeterlik algıları. Ana Dili Eğitimi Dergisi, 1(2), 36-45. 
Şen, E., \& İşigüzel, B. (2018). Türkçenin Yabancı Dil Olarak Öğretiminde Aktif Öğrenmenin Üretici Becerilerin Geliştirilmesine Etkisi (Gem Örneği). Nevşehir Hacı Bektaş Veli Üniversitesi Sosyal Bilimler Enstitüsü,

Tezcan, G., \& Genç, S. Z. (2015). İlköğretim öğretmen adaylarının kariyer planları ve öğretmenlik mesleğine yönelik tutumları. Karadeniz Sosyal Bilimler Dergisi, 7(03), 254-263.

Tiryaki, E. N. (2017). Yabancılara Türkçe Öğretiminde Öğrencilerin Metin Oluşturma Becerilerinin ve Sorunlarının Belirlenmesi. Erzincan Üniversitesi Eğitim Fakültesi Dergisi, 19(1), 21-32.

Triandis, H. C. (2018). Individualism and collectivism: Routledge.

Tunçel, H. (2015). Yabancı Dil Olarak Türkçe Konuşma Kaygısının Çeşitli Değişkenler Açısından İncelenmesi. Hacettepe Üniversitesi Yabancı Dil Olarak Türkçe Araştırmaları Dergisi(2), 107135 .

Yıldırım, A., \& Şimşek, H. (2016). Sosyal bilimlerde nitel araştırma yöntemleri (10. bs.). Ankara: Seçkin Yaymcillk.

Yuanfang, Y. (2009). A study of foreign language learning motivation and achievement: from a perspective of sociocultural theory. CELEA Journal, 32(3), 87-97. 